\title{
Bathtub dynamics: initial results of a systems thinking inventory
}

\author{
Linda Booth Sweeney and John D. Sterman ${ }^{\mathrm{b}}{ }^{\mathrm{a}}$
}

\begin{abstract}
Linda Booth Sweeney is a doctoral candidate at the Harvard Graduate School of Education. Her research investigates how children and adults understand the dynamics of complex systems. Her most recent publications include The Systems Thinking Playbook,

Volumes 1-3 (co-authored with Dennis Meadows) and Systems Thinking for Kids, Big and Small: Understanding How Systems Work Through Favorite Children's Stories, Volume I (in press).

John Sterman is the Standish Professor of Management at the MIT Sloan School and director of the MIT System Dynamics Group.
\end{abstract}

\begin{abstract}
In a world of accelerating change, educators, business leaders, environmentalists and scholars are calling for the development of systems thinking to improve our ability to take effective actions. Through courses in the K-12 grades, universities, business schools, and corporations, advocates seek to teach people to think systemically. These courses range from one-day workshops with no mathematics to graduate level courses stressing formal modeling. But how do people learn to think systemically? What skills are required? Does a particular type of academic background improve one's ability to think systemically? What systems concepts are most readily understood? Which tend to be most difficult to grasp? We describe initial results from an assessment tool or systems thinking inventory. The inventory consists of brief tasks designed to assess particular systems thinking concepts such as feedback, delays, and stocks and flows. Initial findings indicate that subjects from an elite business school with essentially no prior exposure to system dynamics concepts have a poor level of understanding of stock and flow relationships and time delays. Performance did not vary systematically with prior education, age, national origin, or other demographic variables. We hope the inventory will eventually provide a means for testing the effectiveness of training and decision aids used to improve systems thinking skills. We discuss the implications of these initial results and explore steps for future research. Copyright $\odot 2000$ John Wiley \& Sons, Ltd.
\end{abstract}

Syst. Dyn. Rev. 16, 249-286, (2000)

\section{Introduction}

The use of systems thinking and system dynamics is increasing dramatically, yet there is little evidence, or even systematic research, to support educators' and consultants' faith in its efficacy. Partisans of systems thinking and systems dynamics education are convinced that such instruction produces or facilitates important thinking skills. Students are promised to learn "how to better identify issues, make better decisions and to gain knowledge and insight they can share with others in their organization" (Microworlds Inc. brochure 1997). Students are also said to learn "how to get to the roots causes of problematic situations and issues at work within an organization ... and to have better creative problem solving skills" (TLC Team Learning Lab brochure 1998). It is also claimed that with systems thinking skills, "People learn to better understand interdependency and change, and thereby to deal more effectively with the forces that shape the consequences of our actions" (Senge et al. 1999: 32).

\footnotetext{
${ }^{a}$ Harvard University Graduate School of Education. E-mail: Linda_Booth_Sweeney@harvard.edu

b MIT Sloan School of Management. E-mail: jsterman@mit.edu

* Correspondence to: J. D. Sterman, MIT Sloan School of Management, 50 Memorial Drive, E53-531, Cambridge, MA 02142, U.S.A. E-mail: jsterman@mit.edu
} 
Unfortunately, claims that systems thinking interventions can produce beneficial changes in thinking, behavior, or organizational performance have outstripped evaluative research testing these claims. Existing studies include: Bakken et al.'s (1992) study of learning from management flight simulators at a high tech firm; Zulauf's (1995) study of systems thinking and cognition; Cavaleri and Sterman's (1995) evaluation of an intervention in the insurance industry; Vennix's (1996) work on the impact of computer-based learning environments on policy making; Mandinach and Cline's (1994) assessment of a systems thinking project in the K-12 arena; see also Doyle et al. (1996; 1998), Ossimitz (1996), Boutilier (1981), Chandler and Boutilier (1992), Dangerfield and Roberts (1995), and the special issue of System Dynamics Review on systems thinking in education (Gould 1993). Despite these studies, however, there is little consensus, and major questions about people's native systems thinking abilities and the efficacy of interventions designed to develop these capacities remain unanswered.

Moreover, there are as many lists of systems thinking skills as there are schools of systems thinking. Each stresses different concepts, from the ability to deduce behavior patterns and see circular cause-effect relations (Richmond 1993) to the use of "synthesis" to reveal a system's structure (Ackoff and Gharajedaghi 1984), to the view of systems thinking as a discipline of organizational learning for "seeing wholes" (Senge 1990).

Most advocates of systems thinking agree that much of the art of systems thinking involves the ability to represent and assess dynamic complexity (e.g., behavior that arises from the interaction of a system's agents over time), both textually and graphically. Specific systems thinking skills include the ability to:

- understand how the behavior of a system arises from the interaction of its agents over time (i.e., dynamic complexity);

- discover and represent feedback processes (both positive and negative) hypothesized to underlie observed patterns of system behavior;

- identify stock and flow relationships;

- recognize delays and understand their impact;

- identify nonlinearities;

- recognize and challenge the boundaries of mental (and formal) models.

Underlying these systems thinking abilities are more basic skills, which are taught as part of most high school curricula:

- interpreting graphs, creating graphs from data;

- telling a story from a graph, creating a graph of behavior over time from a story;

- identifying units of measure (i.e. Federal Deficit $=\$$ /time period);

- basic understanding of probability, logic and algebra. 
Effective systems thinking also requires good scientific reasoning skills such as the ability to use a wide range of qualitative and quantitative data, and familiarity with domain-specific knowledge of the systems under study. For example, systems thinking studies of business issues require some knowledge of psychology, decision making, organizational behavior, economics, and so on.

The challenge facing educators is not only to develop ways to teach these skills, but also to measure the impact of such courses on students' ability to think dynamically and systemically. Doing so requires instruments to assess students' systems thinking abilities prior to and after exposure to the concepts. In this paper we take first steps toward the development of an inventory of test items that measure people's performance on specific systems thinking concepts. We develop and test items focusing on some of the most basic systems thinking concepts: stocks and flows, time delays, and negative feedback. Additional items under development will address other dimensions of systems thinking.

In this paper we use the inventory to assess understanding of basic systems concepts in subjects with little prior exposure to systems thinking. The subject pool, students at the MIT Sloan School of Management, are highly educated and possess an unusually strong background in mathematics and the sciences compared to the public at large. If their ability to understand such basic concepts as stocks and flows and time delays is poor, the performance of the general public is not likely to be better. As we show, the performance of these students was quite poor and the students exhibited persistent, systematic errors in their understanding of these basic building blocks of complex systems. Broad prevalence of such deficits poses significant challenges to educators and organizations seeking to develop systems thinking or formal models to address pressing issues.

A number of experimental studies examine how people perform in dynamically complex environments. These generally show that performance deteriorates rapidly (relative to optimal) when even modest levels of dynamic complexity are introduced, and that learning is weak and slow even with repeated trials, unlimited time, and performance incentives (e.g., Sterman 1989a, 1989b; Paich and Sterman 1993; Diehl and Sterman 1995. See also Brehmer 1992; Frensch and Funke 1995; and Dörner 1980; 1996). The usual explanation for our poor performance in these studies is bounded rationality: the complexity of the systems we are called upon to manage overwhelms our cognitive capabilities. Implicit in this account is the assumption that, while we are unable to correctly infer how a complex system consisting of many interacting elements and agents will behave or how it should be managed, we do understand the individual building blocks such as stocks and flows and time delays. Our results challenge this view, suggesting that the problems people have with dynamics are more basic and, perhaps, more difficult to overcome. 


\section{Method}

We created several tests to explore students' baseline systems thinking abilities. Each test consisted of a few paragraphs posing a problem. Participants were asked to respond by drawing a graph of the expected behavior over time. The items were designed to be simple and can be answered without use of mathematics beyond high school (primarily simple arithmetic).

\section{Stocks and flows: the Bath Tub/Cash Flow (BT/CF) Task}

Stocks and flows are fundamental to the dynamics of systems (Forrester 1961). Stock and flow stuctures are pervasive in systems of all types, and the stock/flow concept is central in disciplines ranging from accounting to epidemiology. The BT/CF task tests subjects' understanding of stock and flow relationships by asking them to determine how the quantity in a stock varies over time given the rates of flow into and out of the stock. This ability, known as graphical integration, is basic to understanding the dynamics of complex systems.

To make the task as concrete as possible, we used two cover stories: The Bath Tub (BT) condition described a bathtub with water flowing in and draining out (Figure 1); the Cash Flow (CF) condition described cash deposited into and withdrawn from a firm's bank account (Figure 2). Both cover stories describe everyday contexts quite familiar to the subjects. Students are prompted to draw the time path for the quantity in the stock (the contents of the bathtub or the cash account).

Note the extreme simplicity of the task. There are no feedback processes-the flows are exogenous. Round numbers are used, so it is easy to calculate the net flow and quantity added to the stock. The form provides a blank graph for the stock on which subjects can draw their answer. Note also that the numerical values of the rates and initial stock are the same in the BT and CF versions (the only difference is the time unit: seconds for the BT case; weeks for the CF case). ${ }^{1}$

We also tested two different patterns for the flows, a square wave pattern (task 1) and a sawtooth pattern (task 2). Figure 1 shows the square wave; Figure 2 shows the sawtooth. We tested all four combinations of cover story (BT/CF) and inflow pattern (task 1/task 2). In the square wave pattern used in task 1 both inflow and outflow are constant during each segment. This is among the simplest possible graphical integration tasks - if the net flow into a stock is a constant, the stock increases linearly. The different segments are symmetrical, so solving the first (or, at most, first two) segments gives the solution to the remaining segments. We expected that performance on this task would be extremely good, so we also tested performance for the case where the inflow is varying: In BT/CF task 2 the outflow is again constant while the inflow follows a sawtooth wave, rising and falling linearly. Task 2, though still elementary, provides a slightly more difficult test of the subjects' 
Fig. 1. Bath Tub task 1 with a square wave pattern
Consider the bathtub shown below. Water flows in at a certain rate, and exits through the drain at another rate:

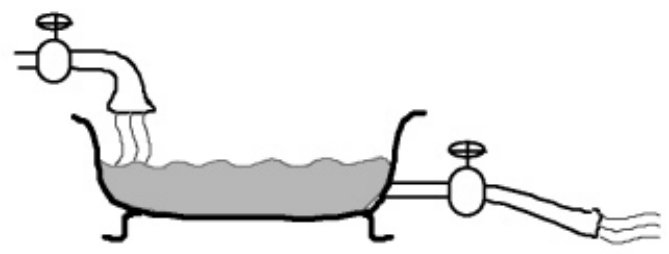

The graph below shows the hypothetical behavior of the inflow and outflow rates for the bathtub. From that information, draw the behavior of the quantity of water in the tub on the second graph below.

Assume the initial quantity in the tub (at time zero) is 100 liters.
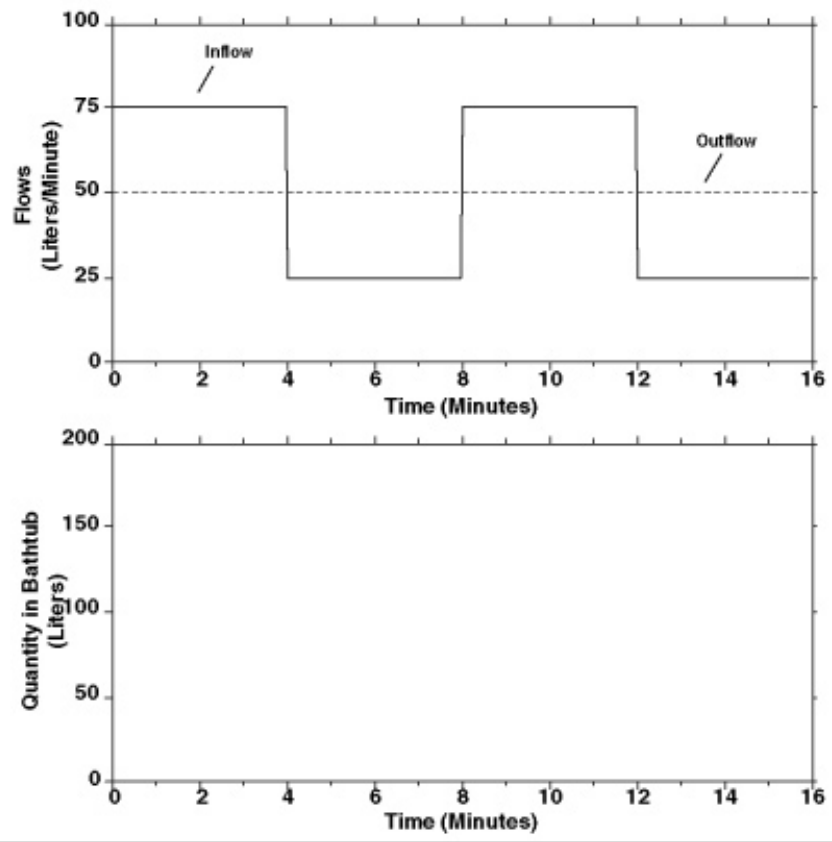

understanding of accumulations, in particular, their ability to relate the net rate of flow into a stock to the slope of the stock trajectory.

\section{Solution to TASK 1}

The correct answer to BT/CF task 1 is shown in Figure 3 (this is an actual subject response). Note the following features: 
Fig. 2. Cash Flow cover story, task 2 with a sawtooth pattern
Consider the cash balance of a company. Receipts flow in to the balance at a certain rate, and expenditures flow out at another rate:

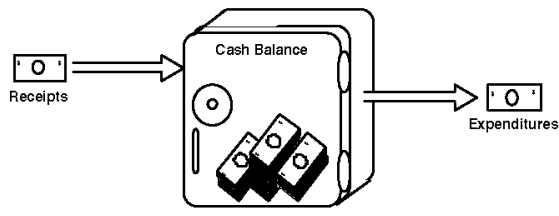

The graph below shows the hypothetical behavior of receipts and expenditures. From that information, draw the behavior of the firm's cash balance on the second graph below.

Assume the initial cash balance (at time zero) is $\$ 100$.
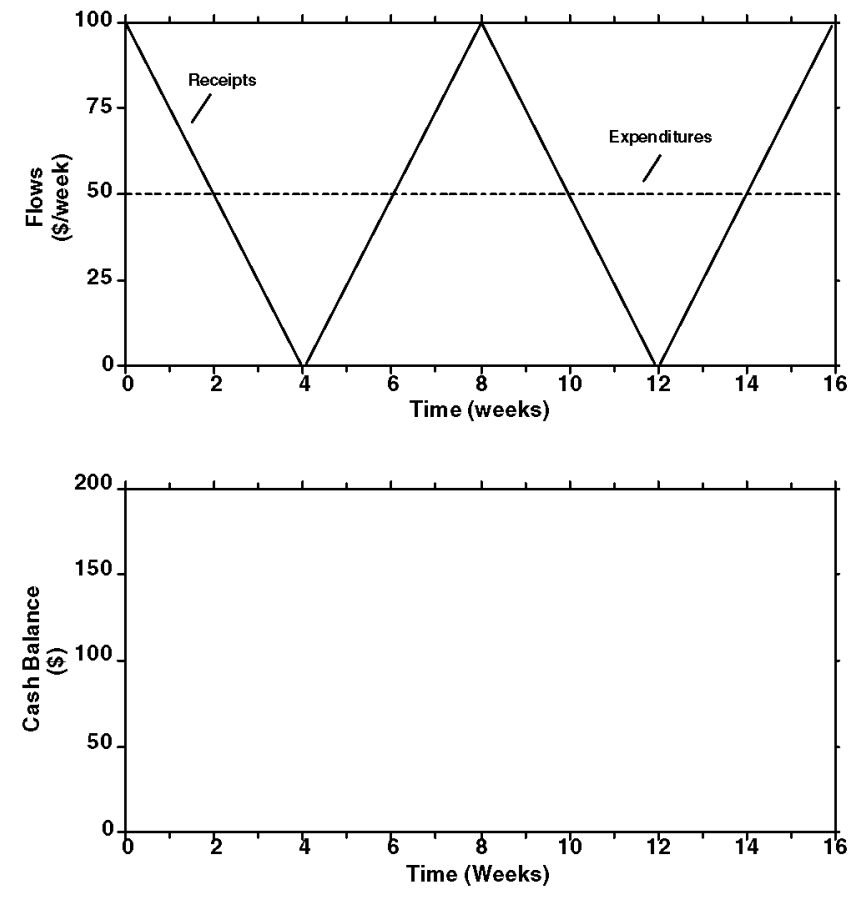

1. When the inflow exceeds the outflow, the stock is rising.

2. When the outflow exceeds the inflow, the stock is falling.

3. The peaks and troughs of the stock occur when the net flow crosses zero (i.e., at $t=4,8,12,16$ ).

4. The stock should not show any discontinuous jumps (it is continuous).

5. During each segment the net flow is constant so the stock must be rising (falling) linearly. 
Fig. 3. A subject response showing the correct answer to $\mathrm{BT} / \mathrm{CF}$ task 1
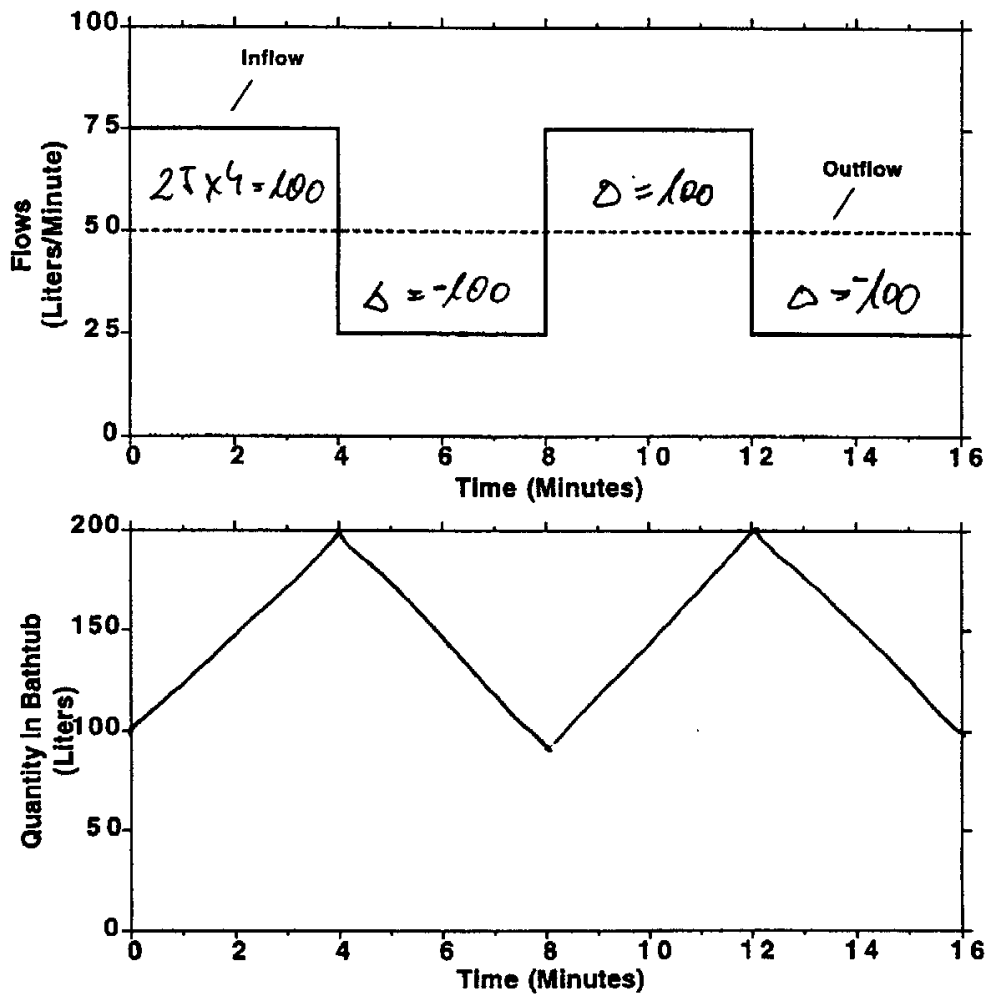

6. The slope of the stock during each segment is the net rate (i.e., \pm 25 units/time period).

7. The quantity added to (removed from) the stock during each segment is the area enclosed by the net rate (i.e., 25 units/time period $\times 4$ time periods $=100$ units, so the stock peaks at 200 units and falls to a minimum of 100 units).

The first five items describe qualitative features of the behavior and do not require even the most rudimentary arithmetic. Indeed, the first three are always true for any stock with any pattern of flows; they are fundamental to the concept of accumulation. The last two describe the behavior of the stock quantitatively, but the arithmetic required to answer them is trivial. Solving the problem is straightforward (the description assumes the BT cover story). First, note that the behavior divides into distinct segments in which the inflow is constant (the outflow is always constant). During segment $1(0<t \leq 4)$ the net inflow is $75-50=25$ liters/second (l/s). Next calculate the total added to the stock by the end of the segment, given by the area bounded by the net rate curve between $0<t \leq 4 \mathrm{~s}$ : $25 \mathrm{l} / \mathrm{s} \times 4 \mathrm{~s}=100$ liters. Finally, since the net flow is 
Fig. 4. A subject response showing the correct answer to $\mathrm{BT} / \mathrm{CF}$ task 2 constant during the segment the stock rises at a constant rate: draw a straight line between the initial stock at 100 liters and the stock at the end of the segment at 200 liters. The slope of this line is $100 / 4=25 \mathrm{l} / \mathrm{s}$. Proceeding to segment $2(4<t \leq 8)$, the inflow drops to $50 \mathrm{l} / \mathrm{s}$ so the net flow is $-25 \mathrm{l} / \mathrm{s}$. The net flow is the same as in segment 1 but with opposite sign, so the stock loses the same quantity between time four and time eight as it gained between time zero and four. If the subject does not notice the symmetry, the same procedure used in segment 1 can be used to determine that the stock loses $100 \mathrm{l}$ by $t=8$. Subsequent segments simply repeat the pattern of the first two.

\section{SOLUTION TO TASK 2}

Figure 4 shows the correct solution to task 2 (again, an actual subject response). The solution must have the following features, which we used to code subject responses and assign a score.

1. When the inflow exceeds the outflow, the stock is rising.

2. When the outflow exceeds the inflow, the stock is falling.

3 . The peaks and troughs of the stock occur when the net flow crosses zero (i.e., at $t=2,6,10,14$ ).
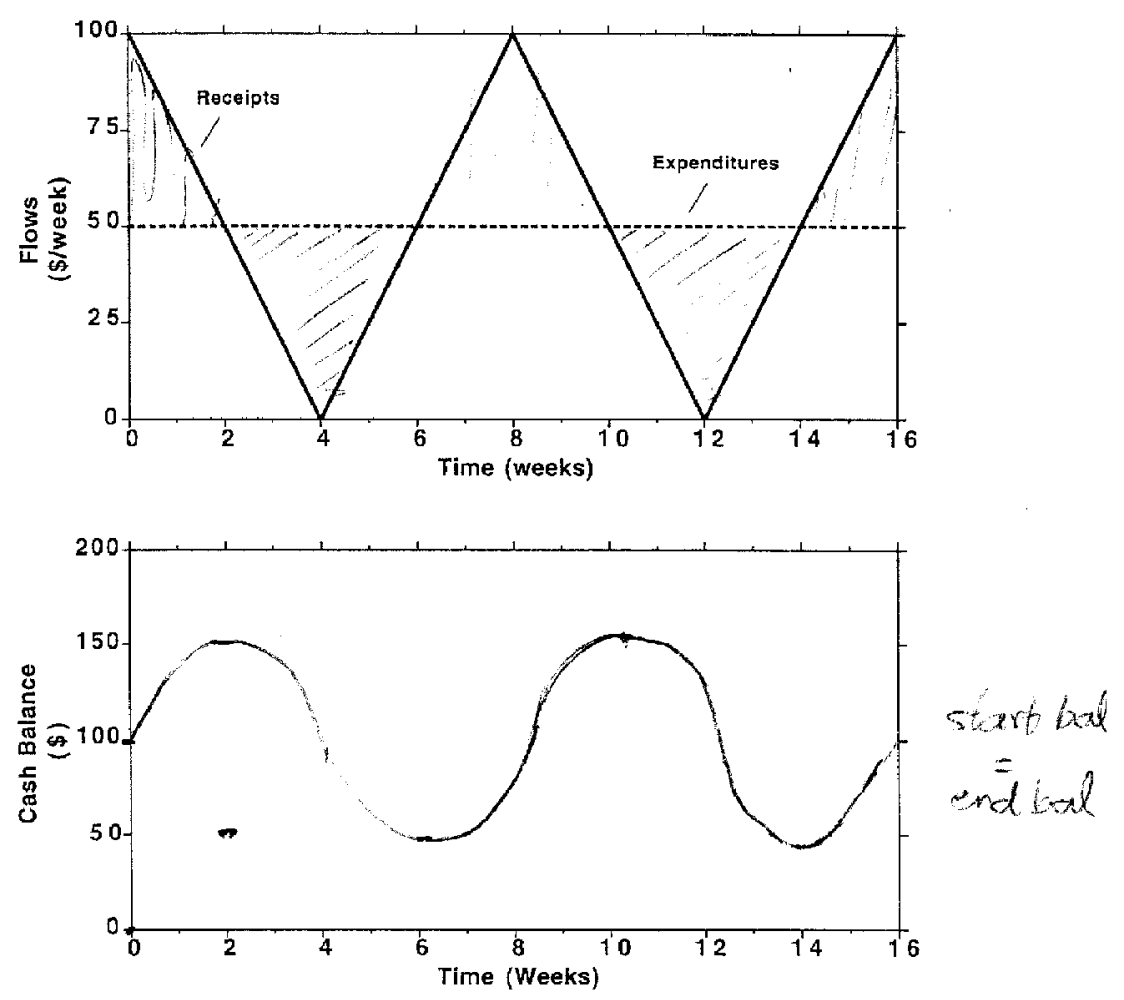
4. The stock should not show any discontinuous jumps (it is continuous).

5. The slope of the stock at any time is the net rate. Therefore:

a. When the net flow is positive and falling, the stock is rising at a diminishing rate $(0<t \leq 2 ; 8<t \leq 10)$.

b. When the net flow is negative and falling, the stock is falling at an increasing rate $(2<t \leq 4 ; 10<t \leq 12)$.

c. When the net flow is negative and rising, the stock is falling at a decreasing rate $(4<t \leq 6 ; 12<t \leq 14)$.

d. When the net flow is positive and rising, the stock is rising at an increasing rate $(6<t \leq 8 ; 14<t \leq 16)$.

6. The slope of the stock when the net rate is at its maximum is 50 units/period $(t=0,8,16)$.

7. The slope of the stock when the net rate is at its minimum is -50 units/period $(t=4,12)$.

8. The quantity added to (removed from) the stock during each segment of two periods is the area enclosed by the net rate (i.e., a triangle with area $\pm(1 / 2) \times 50$ units/period $\times 2$ periods $= \pm 50$ units $)$. The stock therefore peaks at 150 units and reaches a minimum of 50 units.

As in task 1, the first five items describe qualitative features of the behavior and do not require even the most rudimentary arithmetic. The last three describe the behavior of the stock quantitatively, but the arithmetic required is trivial.

Answering the question also requires subjects to read and interpret the graph of the rates, and to add points to an existing graph (the level of the stock at various points in time). For task 2, subjects must also know the formula for the area of a triangle (for item 7) and be able to construct a straight line with slope \pm 50 units/time period to show the slope of the stock properly at the inflection points $t=0,4,8,12$, and 16 (for item 6 ). ${ }^{2}$

\section{The impact of time delays: the Manufacturing Case}

The BT/CF tasks address subjects' understanding of the basic concepts of accumulation, without any feedbacks or time delays. However, feedback processes and time delays are pervasive in complex systems and often have a significant effect on their dynamics. Time delays can cause instability and oscillation, especially when embedded in negative feedback loops. The Manufacturing Case (MC) assesses students' understanding of stock and flow relationships in the presence of a time delay and a single negative feedback loop. The MC task also tests their ability to create a graph that tells a story about a particular behavior over time, and to draw inferences about the dynamics of a system from a description of its structure (Figure 5).

The manufacturing case is an example of a simple stock management task (Sterman 1989a, 1989b). The stock management task is a fundamental structure in many systems and at many levels of analysis, from filling a glass of 
Fig. 5. Manufacturing Case
Consider a manufacturing firm. The firm maintains an inventory of finished product. The firm uses this inventory to fill customer orders as they come in. Historically, orders have averaged 10,000 units per week. Because customer orders are quite variable, the firm strives to maintain an inventory of 50,000 units to provide excellent customer service (that is, to be able to fill essentially $100 \%$ of every order), and they adjust production schedules to close any gap between the desired and actual level. Although the firm has ample capacity to handle variations in demand, it takes time to adjust the production schedule, and to make the product - a total lag of four weeks.

Now imagine that the order rate for the firm's products suddenly and unexpectedly rises by $10 \%$ and remains at the new, higher rate indefinitely, as shown in the graph below. Before the change in demand, production was equal to orders at 10,000 units/week, and inventory was equal to the desired level of 50,000 units.

Sketch the likely path of production and inventory on the graphs below. Provide an appropriate scale for the graph of inventory.
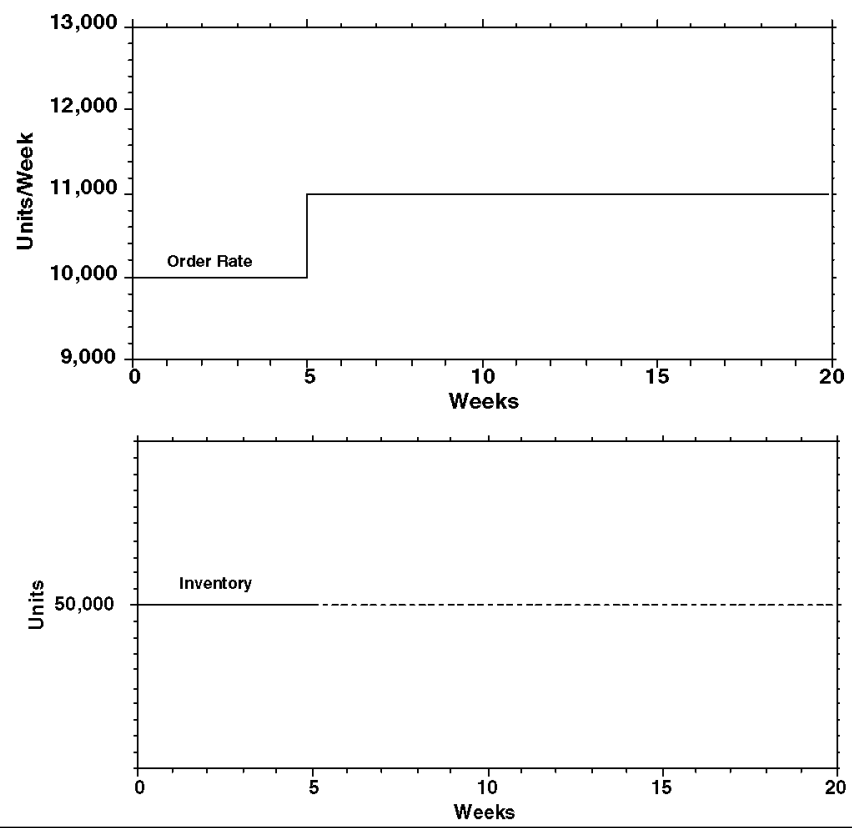

water to regulating your alcohol consumption to inventory control and capital investment (see Sterman 2000, ch. 17 for discussion and examples). In the stock management task, the system manager seeks to maintain a stock at a target or desired level in the face of disturbances such as losses or usage by regulating the inflow to the stock. Often there is a delay between the initiation of a control action and its effect. Here a firm seeks to control its inventory in the face of variable customer demand and a lag between a change in the production 
schedule and the actual production rate. The task involves a simple negative feedback regulating the stock (boosting the inflow to the stock when the stock is less than desired, and cutting it when there is a surplus).

\section{Solution to the Manufacturing CASE}

Unlike the BT/CF tasks, there is no unique correct answer to the MC task. However, the trajectories of production and inventory must follow certain constraints, and their shapes can be determined without any quantitative analysis. The unanticipated step increase in customer orders and production adjustment delay mean shipments increase while production remains, for a time, constant at the original rate. Inventory therefore declines. The firm must not only boost output to the new rate of orders, but also rebuild its inventory to the desired level. Production must therefore overshoot orders and remain above shipments until inventory reaches the desired level, at which point production can drop back to equilibrium at the customer order rate.

Furthermore, since the task specifies that the desired inventory level is constant, the area bounded by the production overshoot must equal the quantity of inventory lost during the period when orders exceed production, which in turn is the area between orders and production (i.e., between week 5 and the point where production rises to the order rate). Figure 6 illustrates. The details are discussed below.

It is possible that production and inventory could fluctuate around their equilibrium values, but while such fluctuation is not inevitable, the overshoot of production is: the only way inventory can rise is for production to exceed orders, in exactly the same way that the only way the level of water in a bathtub can rise is for the flow in from the tap to exceed the flow out through the drain.

A few modest assumptions allow the trajectories of production and inventory to be completely specified. When customer orders increase from 10000 to 11000 widgets/week, production remains constant at the initial rate, as a result of the four week lag. Inventory, therefore, begins to decline at the rate of 1000 widgets/week. What happens next depends on the distribution of the production lag. The simplest case, and the case most subjects assumed, is to assume a pipeline delay, that is: ${ }^{3}$

$$
\operatorname{Production}(t)=\text { Desired Production }(t-4) \text {. }
$$

Assuming that production follows desired production with a four week delay means that production continues at 10000 widgets/week until week 9. During this time, inventory drops by a total of 1000 widgets/week $\times 4$ weeks $=4000$ widgets, thus falling to 46000 widgets. If it is further assumed that the firm understands the delay and realizes that production will remain at its original level for four weeks, management will raise desired production above orders at week 5, keep it above orders until an additional 4000 widgets are scheduled for production, and then bring desired production back down to the level of orders. 
Fig. 6. A correct response to the manufacturing case
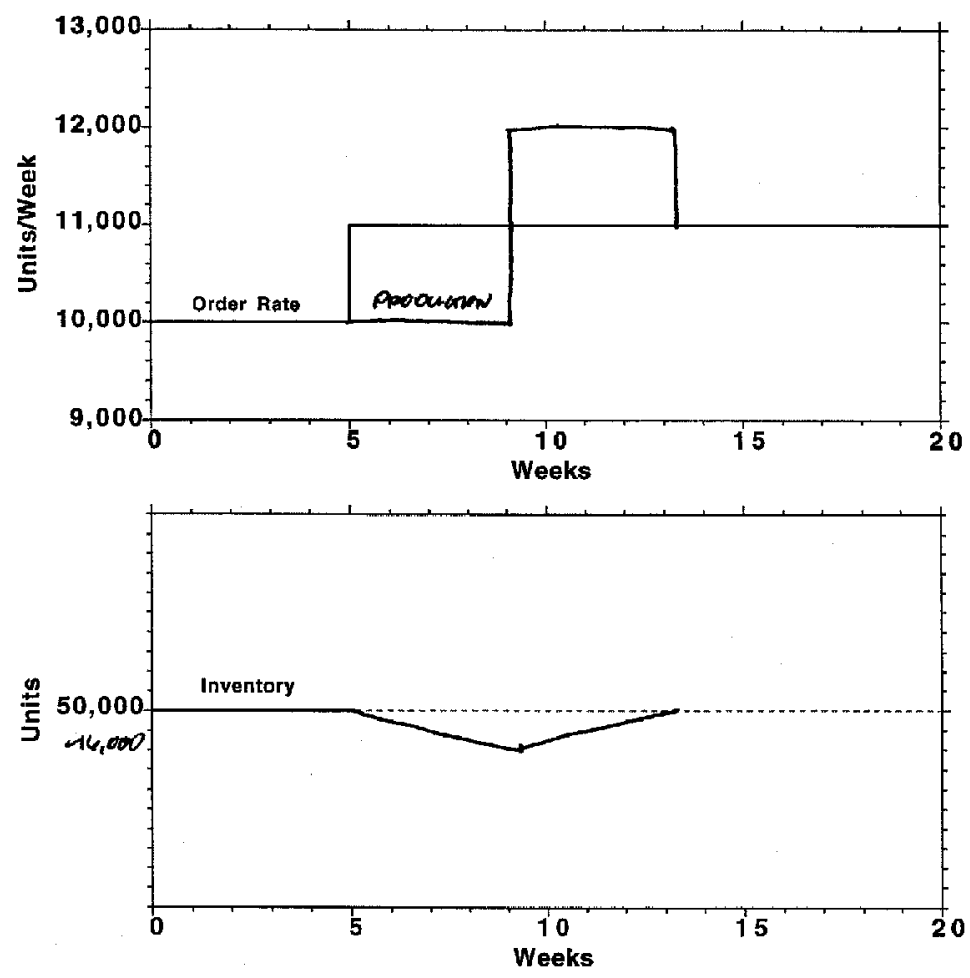

Production then traces this pattern four weeks later. Assuming finally that production remains constant during the period of overshoot gives production trajectories such as those shown in Figures 6 and 7. Figure 6, typical of many correct responses, shows production rising in week 9 to 12000 widgets/week and remaining there for the next four weeks, giving a rectangle equal in shape to that for the period $5<t \leq 9$, when shipments exceed production. Of course, the production overshoot can have any shape as long as the area equals 4000 widgets. Figure 7 shows another correct response, in which the subject shows production rising in week 9 to 13000 widgets/week and remaining there for two weeks. This response clearly shows that the subject understood the task well, particularly the area concept. Very few subjects $(<0.2 \%)$ drew a pattern with the duration of the overshoot $\neq 4$ weeks while also maintaining the correct area relationship.

In the basic version of the task, subjects were asked only to sketch the trajectory of production. Doing so requires them to infer correctly the behavior of the firm's inventory. Without a graph of inventory this might be more difficult for subjects, making it difficult for them to correctly trace the production overshoot. To test this hypothesis we defined an inventory graph treatment with two conditions. In the Inventory graph (I) condition, the page with the MC task included 
Fig. 7. An unusual correct response to the manufacturing case

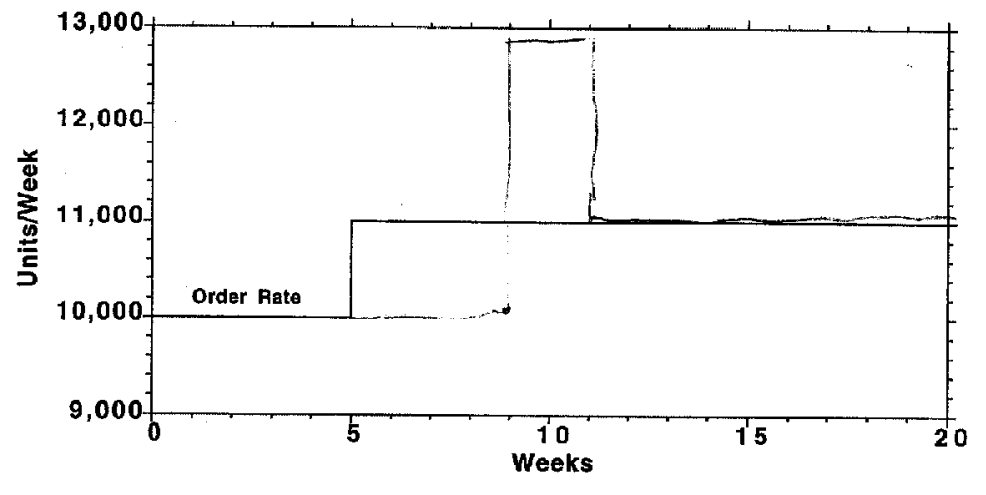

a blank graph for the firm's inventory and subjects were asked to provide trajectories for both production and inventory (as shown in Figure 5). In the no inventory graph $(\sim \mathrm{I})$ condition, subjects were provided only with the graph showing customer orders and were not asked to sketch the trajectory of inventory. ${ }^{4}$

In the $\sim$ I condition performance was assessed by coding for the following criteria:

1. Production must start in equilibrium with orders.

2. Production must be constant prior to time 5 and indicate a lag of four weeks in the response to the step increase in orders.

3. Production must overshoot orders to replenish the inventory lost during the initial period when orders exceed production. Production should return to (or fluctuate around) the equilibrium rate of 11000 widgets/week (to keep inventory at or fluctuating around the desired level).

4. Conservation of material: The area enclosed by production and orders during the overshoot of production (when production $>$ orders) must equal the area enclosed by orders less production (when production < orders).

Points 1 and 2 follow directly from the instructions, which specify that the system starts in equilibrium, that there is a four-week production lag, and that the change in orders is unanticipated. Point 3 results from the firm's policy of adjusting production to correct any inventory imbalance and reflects the basic physics of stocks and flows, specifically that a stock falls when outflow exceeds inflow and rises when inflow exceeds outflow. Point 4 tests conservation of material: since desired inventory is constant the quantity added to inventory during the production overshoot just replaces the quantity lost during the initial response when orders exceed production.

Responses to the inventory graph condition were also coded for the following:

5. Inventory must initially decline (because production $<$ orders).

6. Inventory must recover after dropping initially. 
7. Inventory must be consistent with the trajectory of production and orders, i.e.,

if orders > production, inventory must be falling;

if orders < production, inventory must be rising;

if orders = production, inventory reaches a maximum or minimum;

when the difference between production and orders is a maximum, the inventory trajectory is at an inflection point (steepest absolute value of the slope).

Point 5 follows from points 1 and 2: when orders increase, production must remain at the initial rate as a result of the adjustment delay. Until production increases, orders exceed output so inventory must fall. Inventory should then rebound because the firm seeks to adjust inventory to its desired value (point 6). Point 7 tests the consistency of the production and inventory trajectories, and indicates whether subjects understand that the slope of a stock at any point is its net rate. Note that point 7 does not require the production trajectory to be correct, only that the trajectory of inventory be consistent with the production path drawn by the subject, whatever it may be.

\section{Subjects and procedure}

We administered the tasks above to two groups of students at the MIT Sloan School of Management enrolled in the introductory system dynamics course. The first group received a background information sheet, the manufacturing case, and the 'paper fold' case on the first day of class. ${ }^{5}$ Two weeks later, the same class received the bath tub cash/flow case. ${ }^{6}$ On the first day of the next semester a new set of students received the background information sheet and bathtub/cash flow task 2 . Students were given approximately 10 minutes in each session. They were told that the purpose of the questions was to illustrate important systems thinking concepts they were about to study and to develop a tool to assess systems thinking skills. Students were not paid or graded.

To explore whether performance on the tasks varied with educational background or other demographic factors, we asked the subjects to fill out a background data sheet. We requested information on their academic background, current degree program, whether English was their first language, their country of origin, and whether they had previously played the beer distribution game (Sterman 1989b; Senge 1990). To protect student privacy, ID codes were assigned and used instead of names in coding and analysis. Table 1 summarizes the subject demographics.

The two groups were quite similar. They were largely comprised of male MBA students, but also included students in other master's degree programs, Ph.D. students, undergraduates, and students cross-registered from graduate programs at other local universities, primarily Harvard. More than half had 
Table 1. Subject demographics. All entries are percentages. Totals may not equal 100 percent due to rounding

\begin{tabular}{|c|c|c|c|}
\hline & $\begin{array}{c}\text { Group 1. Session } 1 \\
\text { MC \& PF } \\
n=225\end{array}$ & $\begin{array}{c}\text { Group } 1 . \text { Session } 2 \\
\text { BT/CF T1 } \\
n=143\end{array}$ & $\begin{array}{c}\text { Group 2. Session } 1 \\
\text { BT/CF T2 } \\
n=150\end{array}$ \\
\hline \multicolumn{4}{|l|}{ Age } \\
\hline $19-24$ & 14 & 13 & 10 \\
\hline $25-30$ & 53 & 49 & 59 \\
\hline $31-35$ & 30 & 34 & 20 \\
\hline 36 and up & 4 & 4 & 11 \\
\hline \multicolumn{4}{|l|}{ Gender } \\
\hline $\mathrm{M}$ & 73 & 71 & 76 \\
\hline $\mathrm{F}$ & 27 & 29 & 24 \\
\hline \multicolumn{4}{|l|}{ Student status } \\
\hline 1st/2nd yr. MBA & 56 & 56 & 37 \\
\hline Executive MBA $^{\mathrm{a}}$ & 11 & 11 & 16 \\
\hline $\mathrm{LFM}^{\mathrm{b}}$ & 8 & 10 & 16 \\
\hline Other $^{\mathrm{c}}$ & 25 & 24 & 32 \\
\hline \multicolumn{4}{|l|}{ Prior field of study } \\
\hline Business/management & 17 & 16 & 27 \\
\hline Engineering & 40 & 43 & 45 \\
\hline Social Sciences & 23 & 22 & 4 \\
\hline Science & 7 & 5 & 10 \\
\hline Computer science & 6 & 7 & 5 \\
\hline Math & 4 & 4 & 6 \\
\hline Humanities & 2 & 3 & 4 \\
\hline \multicolumn{4}{|l|}{ Highest prior degree } \\
\hline BA & 22 & 23 & 17 \\
\hline BS & 35 & 36 & 43 \\
\hline MA/MS & 30 & 27 & 28 \\
\hline Ph.D. & 6 & 7 & 5 \\
\hline High school & 2 & 2 & 2 \\
\hline BE, JD, BBA, MD & 2 & 2 & 1 \\
\hline BA \& BS & 3 & 3 & 3 \\
\hline \multicolumn{4}{|l|}{ Region of origin } \\
\hline \multicolumn{4}{|l|}{ North America } \\
\hline (+ Australia/New Zealand) & 35 & 36 & 50 \\
\hline Europe & 19 & 20 & 16 \\
\hline Asia and Middle East & 32 & 29 & 22 \\
\hline Latin America & 13 & 14 & 10 \\
\hline Africa & 1 & 1 & 2 \\
\hline \multicolumn{4}{|l|}{ English } \\
\hline First language & 44 & 44 & 54 \\
\hline Not first language & 56 & 56 & 46 \\
\hline \multicolumn{4}{|l|}{ Beer game experience } \\
\hline Played before & 61 & 62 & 62 \\
\hline Have not played & 39 & 38 & 38 \\
\hline
\end{tabular}

a The executive MBA students were enrolled in a various one-year degree programs at MIT and are typically mid-career executives with extensive business experience.

${ }^{\mathrm{b}}$ LFM = Leaders for Manufacturing, a dual degree program awarding both an MBA and MS in engineering.

c 'Other' includes Ph.D. and graduate students from other MIT departments (averaging about 12 percent), graduate students from other universities (primarily Harvard), averaging about 10 percent, and MIT undergraduates (about 5 percent).

d PF = Paper fold task, the results of which are not described in this paper. See note 5.

undergraduate backgrounds in engineering, computer science, mathematics, or the sciences, with most of the rest having business or a social science (primarily economics) as their undergraduate field of study. Fewer than 5 percent had 
degrees in the humanities. The students are highly international, with 35 countries represented. In group 1 English was a first language for about 44 percent; in group 2 these proportions were roughly reversed. Prior to taking the test, more than half the subjects had played the beer game as part of Sloan's MBA orientation program. These demographics are typical of the Sloan School's student body.

Initial coding criteria were developed, then tested on a subsample of results. The coding criteria were revised to resolve ambiguities; the final coding criteria are described above. Correct responses to each criterion were assigned 1 and incorrect responses were given zero.

\section{RESULTS}

Table 2 summarizes overall performance. In general, performance is poor.

\section{Bath Tub/Cash Flow, task 1}

Average performance on this simplest graphical integration task was 77 percent. Table 3 breaks performance down by the individual coding criteria and cover story. Subjects did best showing the stock trajectory as a continuous curve with peaks and troughs at the correct times. They did worst on items 6 and 7, which test the basic concepts that the net rate is the slope of the stock and that the area enclosed by the net rate in any interval is the quantity added to the stock during the interval. One fifth did not correctly show the stock rising (falling) when the inflow was greater than (less than) the outflow. More than a fifth failed to show the stock rising and falling linearly during each segment, though the net rate was constant. Nearly two fifths failed to relate the net flow over each interval to the change in the stock. These concepts are the

Table 2. Average performance by task. Performance is the mean fraction of correct coding criteria

\begin{tabular}{lrcc}
\hline Task & $N$ & Mean & $\sigma$ \\
\hline BT/CF task 1 & 182 & 0.77 & 0.34 \\
BT & 95 & 0.83 & 0.29 \\
CF & 87 & 0.69 & 0.37 \\
$H_{0}:$ BT = CF & & $t=2.94, p<0.004$ & \\
BT/CF task 2 & 150 & 0.48 & 0.35 \\
BT & 79 & 0.46 & 0.36 \\
CF & 71 & 0.51 & 0.35 \\
$H_{0}:$ BT = CF & & $t=0.86, p<0.39$ & \\
Manufacturing Case & 225 & 0.41 & 0.28 \\
No Inventory Graph & 116 & 0.50 & 0.27 \\
Inventory Graph & 109 & 0.32 & 0.26 \\
$H_{0}:$ I = I & & $t=5.11, p<0.0001$ & \\
\hline
\end{tabular}


Table 3. Performance on Bath Tub/Cash Flow task 1. The $\chi^{2}$ statistic tests the hypothesis that performance on the two treatment conditions is the same

Fig. 8. Typical erroneous subject responses to $\mathrm{BT} / \mathrm{CF}$ task 1

\begin{tabular}{|c|c|c|c|c|c|}
\hline Criterion & Average & $\mathrm{BT}$ & $\mathrm{CF}$ & $\chi^{2}$ & $p$ \\
\hline $\begin{array}{l}\text { 1. When the inflow exceeds the outflow, the stock is } \\
\text { rising. }\end{array}$ & 0.80 & 0.87 & 0.72 & 0.05 & 0.83 \\
\hline $\begin{array}{l}\text { 2. When the outflow exceeds the inflow, the stock is } \\
\text { falling. }\end{array}$ & 0.80 & 0.86 & 0.73 & 0.83 & 0.36 \\
\hline $\begin{array}{l}\text { 3. The peaks and troughs of the stock occur when the } \\
\text { net flow crosses zero (i.e., at } t=4,8,12,16 \text { ). }\end{array}$ & 0.86 & 0.89 & 0.81 & 0.41 & 0.52 \\
\hline $\begin{array}{l}\text { 4. The stock should not show any discontinuous jumps } \\
\text { (it is continuous). }\end{array}$ & 0.89 & 0.96 & 0.82 & 0.02 & 0.89 \\
\hline $\begin{array}{l}\text { 5. During each segment the net flow is constant so the } \\
\text { stock must be rising (falling) linearly. }\end{array}$ & 0.78 & 0.84 & 0.72 & 1.61 & 0.21 \\
\hline $\begin{array}{l}\text { 6. The slope of the stock during each segment is the net } \\
\text { rate (i.e., } \pm 25 \text { units/time period). }\end{array}$ & 0.66 & 0.73 & 0.58 & 1.57 & 0.21 \\
\hline $\begin{array}{l}\text { 7. The quantity added to (removed from) the stock } \\
\text { during each segment is the area enclosed by the net } \\
\text { rate (i.e., } 25 \text { units/time period } \times 4 \text { time } \\
\text { periods }=100 \text { units, so the stock peaks at } 200 \text { units } \\
\text { and falls to a minimum of } 100 \text { units). }\end{array}$ & 0.63 & 0.68 & 0.56 & 0.71 & 0.40 \\
\hline Mean for all items & 0.77 & 0.83 & 0.69 & $t=2.94$ & 0.004 \\
\hline
\end{tabular}

most basic and intuitive features of accumulation. Further, they are the fundamental concepts of calculus, a subject all MIT students are required to have. It is possible that their poor performance arose from numerical errors in the required computations, but the arithmetic required is modest and examination of the responses suggests conceptual confusion, not arithmetical error.

Figure 8 illustrates typical errors for BT/CF Task 1. In Figure 8(a), the subject shows the stock changing discontinuously, jumping up and down in phase
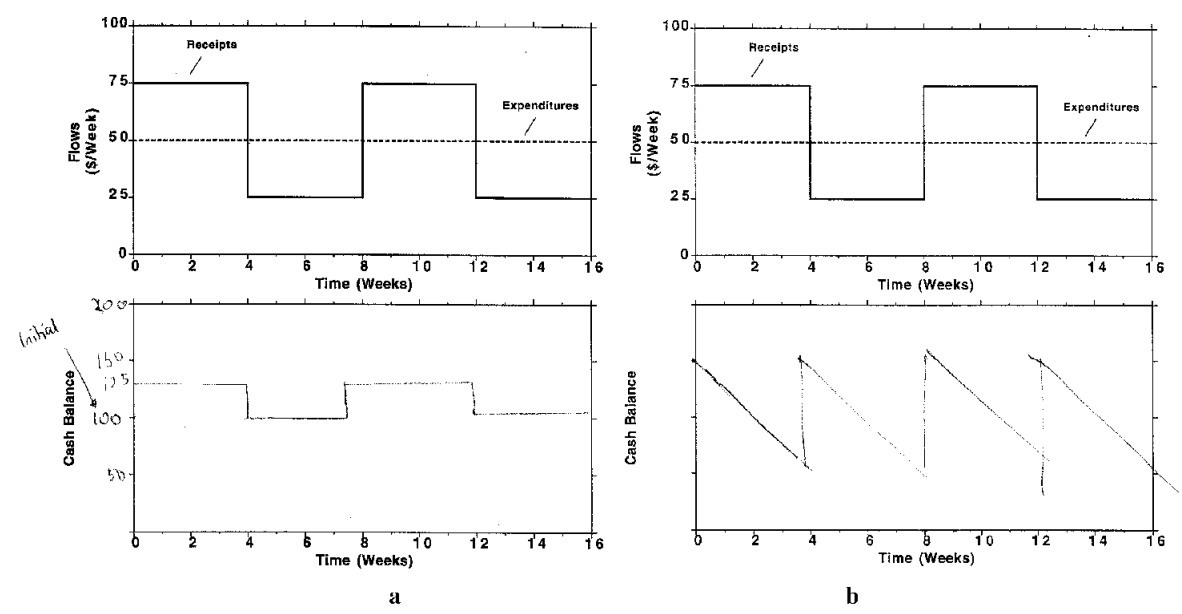

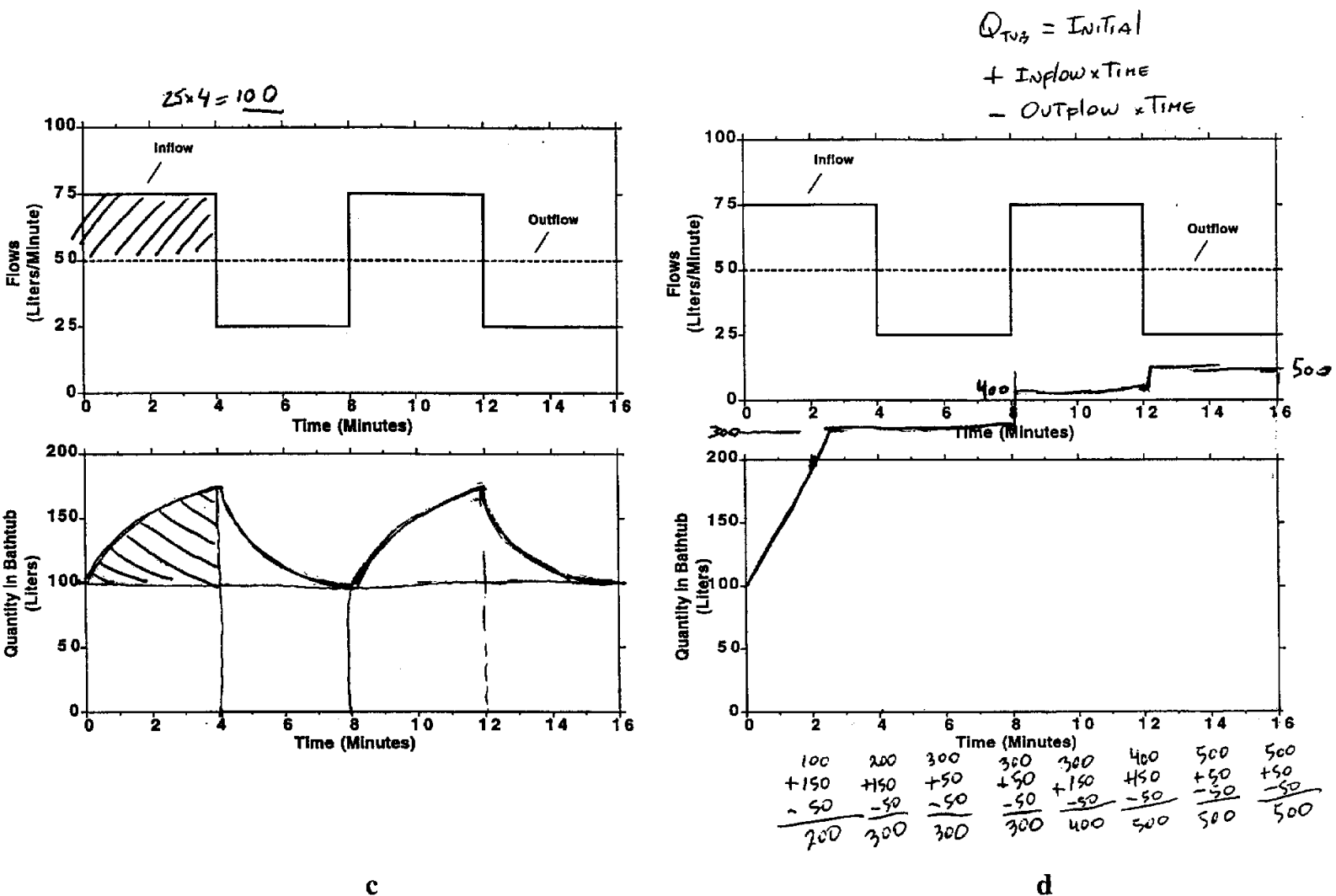

Fig. 8. (continued)

with the net rate (11 percent of the subjects exhibited such discontinuities). The subject shows the stock as constant in each interval even though the net flow is nonzero. Figure 8(b) is the answer from an even more confused subject, who shows the stock falling linearly during each interval, whether the net flow is positive or negative, then suddenly jumping up at each transition point. These responses suggest subjects are confused about the definitions of stocks and flows and do not understand the basic relationship between a net flow and the rate of change of a stock, in particular, that the change in the stock over an interval is the area bounded by the net rate in the interval. Instead, as illustrated by Figure 8(a), it appears the subject drew a stock trajectory whose shape matched the shape of the net rate.

Figure 8(c) shows a subject who understands something about the area swept out by the net rate (note the hashmarks in the rectangle enclosed by the inflow and outflow between time 0 and time 4). The subject correctly shows the stock rising when it should be rising and falling when it should be falling, but 
Fig. 8. (continued)
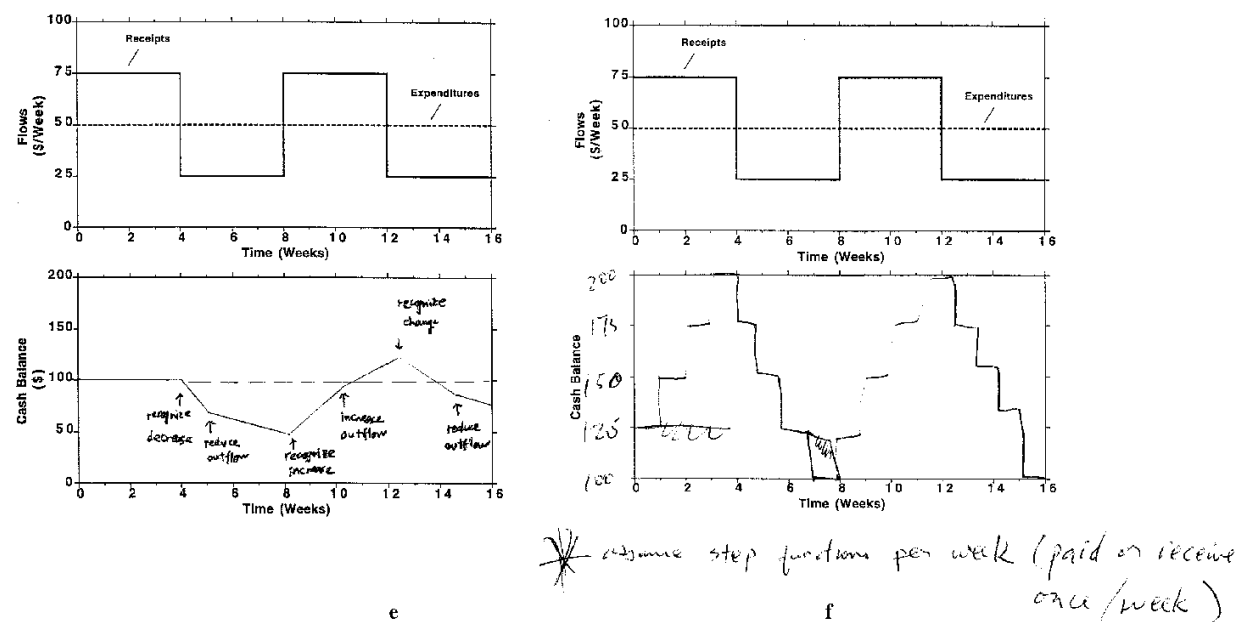

draws the stock in each interval as rising or falling at a diminishing rather than linear rate. The subject also draws hashmarks in the area enclosed by the stock trajectory. The area under the stock curve has no relevance, suggesting confusion about the relationship between the net rate and the slope of the stock.

The subject in Figure 8(d) wrote the following equation:

$$
Q_{\text {tub }}=\text { Initial }+ \text { Inflow } \times \text { Time }- \text { Outflow } \times \text { Time },
$$

which is correct for the case of constant inflows and outflows, if the Time referred to is the length of each interval (4 minutes). While this equation shows some understanding of the area rule, the subject then proceeds to show an impressive array of incorrect intermediate calculations and draws a trajectory in which the stock never falls. Figure 8(e) similarly shows a thoroughly confused subject who received the cash flow cover story. Note the markings "recognize decrease" and "recognize increase." The subject appears to assume that there is a four-week delay in recognizing revenue and expenditures, suggesting confusion between the actual and perceived flows, or between actual payments and expenditures and the way an accounting system might report them. A number of subjects appeared to be confused by these issues. Figure 8(f) shows a response in which the subject assumes that the flows are discrete, with revenues and expenditures only occurring at the end of every week. The subject writes "Assume step function per week (paid or receive once/week)." These subjects suffer from "spreadsheet thinking"-assuming that change occurs suddenly between time periods, as in a spreadsheet where time is broken into discrete intervals. Interestingly, the vast majority of subjects who exhibited spreadsheet thinking received the cash flow cover story. Subjects apparently had an easier time imagining continuous flows of water than money. 
Table 4. Performance on Bath Tub/Cash Flow task 2
These subjects appear to confuse the common practice of reporting financial accounts only at the end of each week, month, or quarter with the underlying reality that financial transactions occur throughout each business day or even around the clock.

\section{Bath Tub/Cash Flow, task 2}

Subjects found the sawtooth pattern for the inflow in task 2 considerably more difficult. Average performance was 48 percent. Table 4 shows performance by individual coding criterion and cover story. In general, subjects did worse on comparable items than in Task 1. For example, fewer than half correctly show the stock rising (falling) when the inflow exceeds (is less than) the outflow, compared to 80 percent in Task 1 . Only 40 percent place the peaks and troughs of the stock at the right times, compared to 86 percent in task 1. Only 37 percent correctly relate the net rate over each interval to the change in the stock over the interval, compared to 63 percent in Task 1 . Only 28 percent correctly relate the net rate to the slope of the stock. In Task 1, where the stock is changing linearly, 78 percent draw it correctly. Fewer than half correctly show the maximum slope for the stock in task 2 . The only item where subjects did better in Task 2 than Task 1 is showing the stock trajectory as continuous: All but 2 of 150 subjects (1.3 percent) did this correctly while 11 percent in

\begin{tabular}{|c|c|c|c|c|c|}
\hline Criterion & Average & BT & $\mathrm{CF}$ & $\chi^{2}$ & $p$ \\
\hline $\begin{array}{l}\text { 1. When the inflow exceeds the outflow, the stock is } \\
\text { rising. }\end{array}$ & 0.47 & 0.46 & 0.48 & 0.05 & 0.83 \\
\hline $\begin{array}{l}\text { 2. When the outflow exceeds the inflow, the stock is } \\
\text { falling. }\end{array}$ & 0.44 & 0.41 & 0.48 & 0.83 & 0.36 \\
\hline $\begin{array}{l}\text { 3. The peaks and troughs of the stock occur when the } \\
\text { net flow crosses zero (i.e., at } t=2,6,10,14 \text { ). }\end{array}$ & 0.40 & 0.41 & 0.39 & 0.02 & 0.89 \\
\hline $\begin{array}{l}\text { 4. The stock should not show any discontinuous jumps } \\
\text { (it is continuous). }\end{array}$ & 0.99 & 0.99 & 0.99 & 0.00 & 1.00 \\
\hline 5. The slope of the stock at any time is the net rate. & 0.28 & 0.25 & 0.30 & 0.41 & 0.52 \\
\hline $\begin{array}{l}\text { 6. The slope of the stock when the net rate is at its } \\
\text { maximum is } 50 \text { units/period }(t=0,8,16) \text {. }\end{array}$ & 0.47 & 0.42 & 0.52 & 1.60 & 0.21 \\
\hline $\begin{array}{l}\text { 7. The slope of the stock when the net rate is at its } \\
\text { minimum is }-50 \text { units/period }(t=4,12) \text {. }\end{array}$ & 0.45 & 0.41 & 0.51 & 1.60 & 0.21 \\
\hline $\begin{array}{l}\text { 8. The quantity added to (removed from) the stock } \\
\text { during each segment of } 2 \text { periods is the area } \\
\text { enclosed by the net rate (i.e., a triangle with area } \\
\pm(1 / 2) \times 50 \text { units/period } \times 2 \text { periods }= \pm 50 \text { units). } \\
\text { The stock therefore peaks at } 150 \text { units and reaches a } \\
\text { minimum of } 50 \text { units. }\end{array}$ & 0.37 & 0.34 & 0.41 & 0.71 & 0.40 \\
\hline Mean for all items & 0.48 & 0.46 & 0.51 & $t=0.86$ & 0.39 \\
\hline
\end{tabular}


Fig. 9. Typical erroneous subject responses to $\mathrm{BT} / \mathrm{CF}$ task 2
Fig. 9. (continued)
Task 1 drew a stock trajectory with discontinuous jumps. Note that the net rate in Task 2 is continuous, while in Task 1 it is discontinuous, suggesting that many subjects drew stock trajectories that matched the pattern of the net rate.

Figure 9 illustrates typical errors in BT/CF Task 2. Figure 9(a) shows the most common. The subject correctly computes the quantity added to the stock during each interval of two periods (note the hash marks highlighting the area of the triangle enclosed by the net rate) and correctly places crosses showing
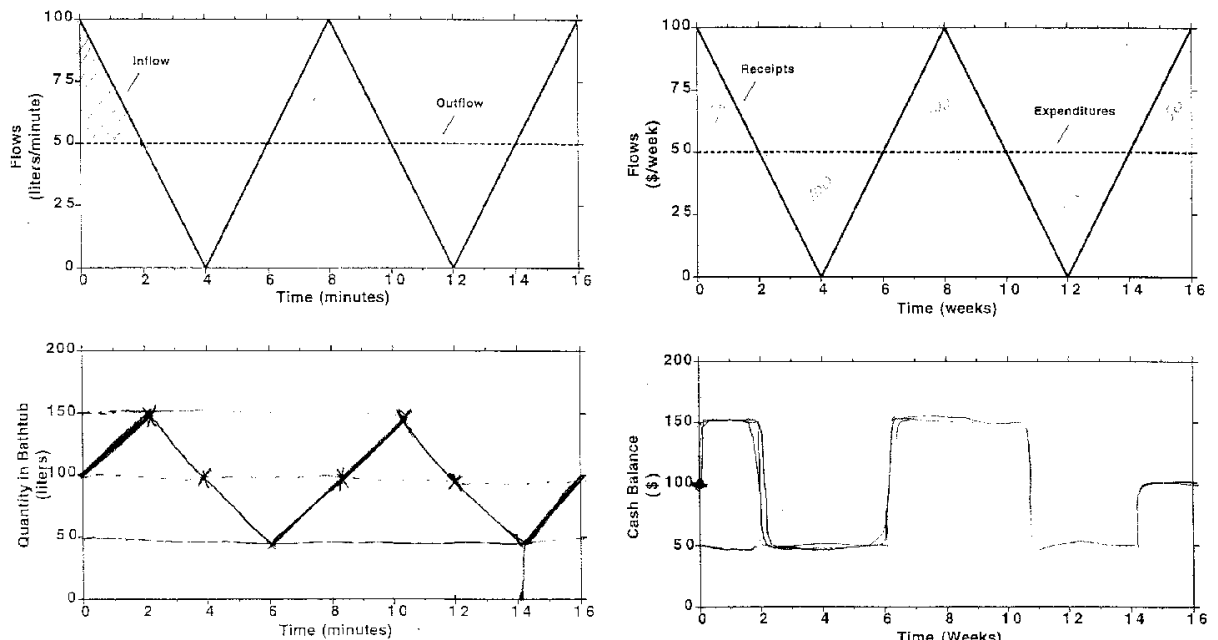

a

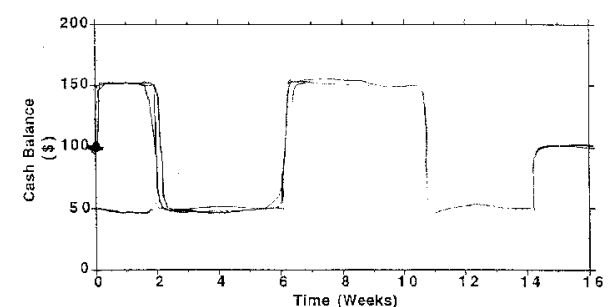

b
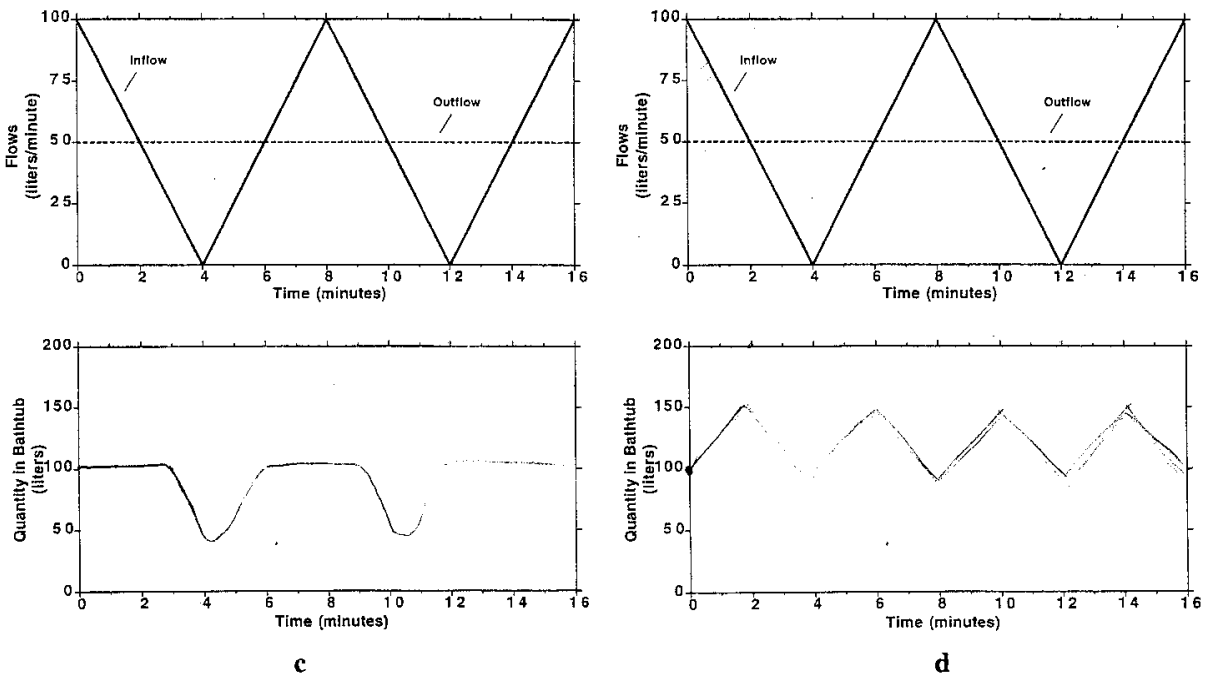
Fig. 9. (continued)
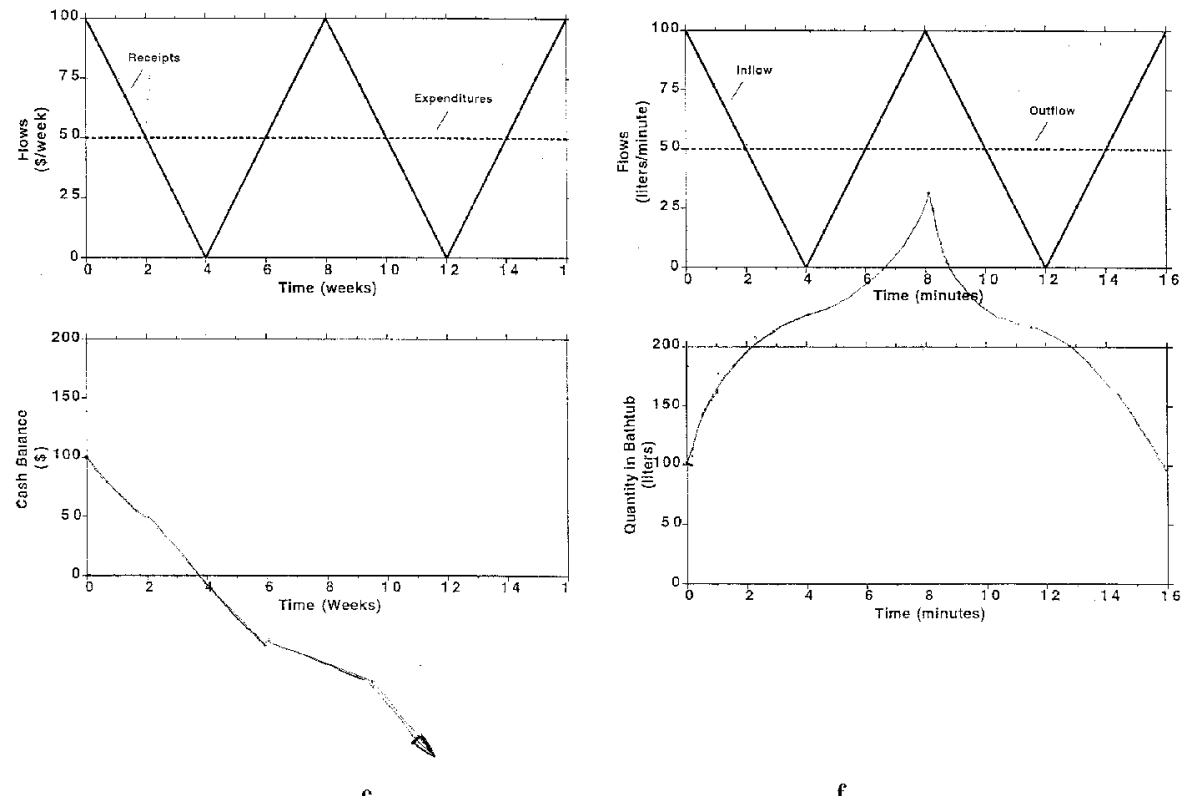

f

Fig. 9. (continued)
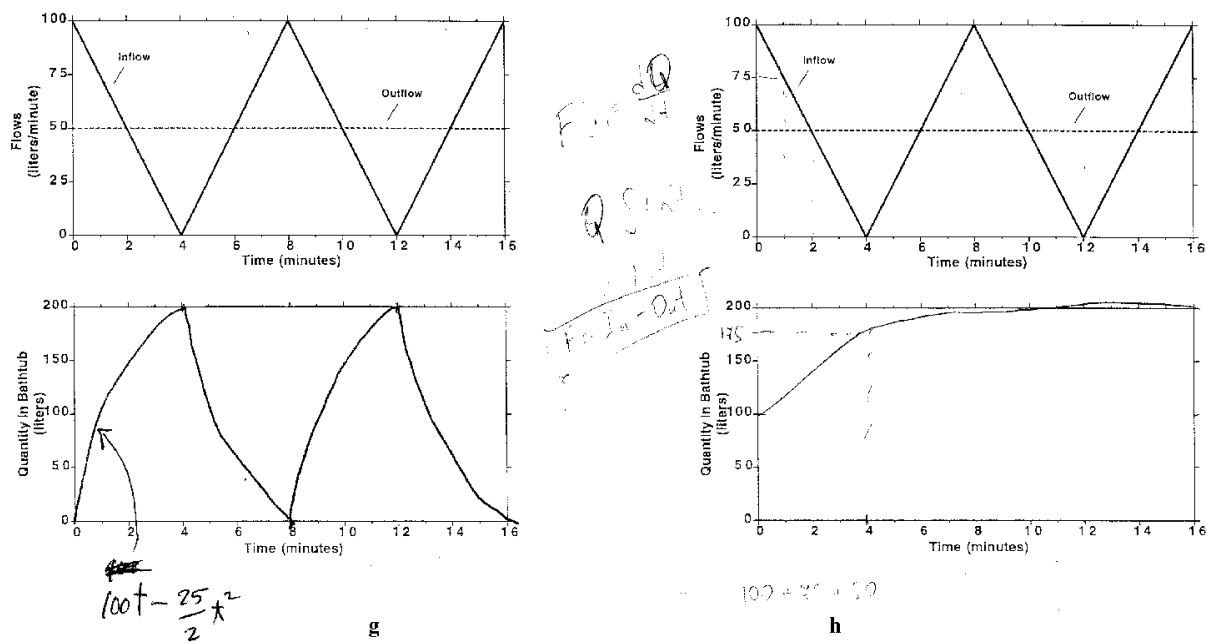

$109+\cdots$
$h$

the value of the stock at $t=2,4,6$, etc. However, the subject then drew straight lines between these points, insensitive to the fact that the net rate is not constant during each interval.

The response shown in Figure 9(a), like that in Figure 8(a), shows the stock jumping discontinuously between high and low values. The subject shows the 
stock at a high, constant value when the net rate is positive and at a lower constant value when the net rate is negative. As noted above, only two subjects in Task 2 drew patterns with discontinuities in the stock trajectory, a much smaller fraction than in Task 1.

The subject in Figure 9(c) shows the stock constant when the net flow is rising, then following the shape of the inflow when it is negative. There is little evidence the subject understands any of the basic stock-flow relationships, nor that the subject has correctly calculated the net rate.

In Figure 9(d) the subject correctly shows the stock rising through $t=2$ and falling from $2 \leq t<4$ by the correct quantities, though the subject incorrectly shows the stock rising and falling linearly, as in Figure 9(a). However, when the net flow is negative but rising (from $4 \leq t<6$ ), the subject shows the stock increasing when in fact it is falling at a diminishing rate. The subject then shows the stock falling from $6 \leq t<8$ when it is rising at an increasing rate. The subject continues in this fashion, creating an oscillation in the stock with half the period of the net rate. Approximately 5 percent of the subjects drew such frequency-doubled patterns, revealing failures to understand the relationship between the net rate and both the magnitude and sign of the slope of the stock.

Figures 9(e) and (f) show some common errors in which the subjects appear to compute the net rate incorrectly and also fail to understand the relationship between the net rate and the slope of the stock. In Figure 9(c) the subject apparently believes the net rate is always negative. Worse, the changes in the slope of the stock do not correspond to those indicated by the flows. In Figure 9(f) the subject apparently ignores the outflow. Up to time 8 the subject's stock trajectory is approximately correct for the case where the outflow is ignored. However, beyond time 8 the subject suddenly assumes that the net rate is negative and shows the stock falling, indicating greater confusion than simply ignoring the outflow.

The subject whose response is shown in Figure 9(g) was one of a number who attempted to solve the problem analytically. This subject clearly understands that the stock is the integral of the flows, and writes a formula, $100 t-(25 / 2) t^{2}$, for the integral of the net flow between $0 \leq t<4$. However, this formula is incorrect. The actual net flow prior to $t=4$ is:

$$
\text { Inflow }- \text { Outflow }=(100-25 t)-50=50-25 t .
$$

Integrating and adding the initial stock of 100 liters yields $100+50 t-(25 / 2) t^{2}$. The subject is on the right track, but fails to account for both the outflow of $50 \mathrm{l} / \mathrm{m}$ and the initial quantity in the tub. While the subject correctly plots the incorrect formula up to time 4, the subject then shows the stock falling over the next four periods, which is inconsistent with the assumption that the subject has ignored the outflow. The subject's intuitive understanding of accumulation was apparently too weak to reveal the error in the calculations. 
The subject in Figure 9(h) writes several equations in the margin, including

$$
\begin{aligned}
& F=\mathrm{d} Q / \mathrm{d} t \\
& Q=\int F \mathrm{~d} t \\
& F=\text { In }- \text { Out. }
\end{aligned}
$$

These are correct and show clear understanding of the relationship between the stock and its flows. However, the subject draws a curve bearing no relationship to the correct response. This subject has a Ph.D. in physics.

The effects of the cover story (Bath Tub vs Cash Flow) are mixed. In Task 1 (the square wave), overall performance is significantly better in the bath tub condition $(t=2.94, p<0.004)$. However, while subjects with the bathtub cover story outperformed those with the cash flow cover story on every one of the individual coding categories, the individual differences are not significant. For Task 2 (the sawtooth), there is no significant difference between performance on the BT and CF treatments on any of the individual criteria or overall.

\section{Manufacturing Case}

Though more difficult that the BT/CF tasks, this task is still quite simple, involving only one stock, one time delay, and one negative feedback loop. Further, the make-to-stock system is a basic paradigm in manufacturing; many of the subjects had previously taken operations management or had relevant experience with real systems of this type. Nevertheless, performance is quite poor. Average performance was 41 percent. Table 5 shows performance by individual coding criteria and treatment condition. About half the subjects failed to show the system starting in the proper equilibrium or a lag between the change in orders and the response of production. Only 44 percent showed production overshooting orders. Instead, most showed production adjusting with a lag to the new customer order rate but not overshooting, indicating that they fail to understand that building inventory back up to its desired level requires production to exceed orders. Shockingly, 89 percent drew production trajectories that violate the required conservation of material, showing no production overshoot or an overshoot with an area that does not equal the area of the production undershoot they drew. Among those receiving the inventory graph condition, 68 percent correctly show inventory initially declining, but only 56 percent show it subsequently recovering. And 90 percent drew production paths inconsistent with their inventory trajectory.

Figure 10 shows typical erroneous responses. Figures 10(a) and (b) show the most common error. Both subjects show production responding with a lag, but rising up only to the new level of orders. There is no production overshoot. Further, both draw inventory trajectories inconsistent with the production path they chose. In Figure 10(a), inventory immediately jumps to 55000 and remains 
Table 5. Performance on the Manufacturing Case

\begin{tabular}{|c|c|c|c|c|c|c|c|c|c|}
\hline Criterion & Average & $\sim \mathrm{I}$ & I & $\chi^{2}$ & $p$ & BG & $\sim \mathrm{BG}$ & $\chi^{2}$ & $p$ \\
\hline $\begin{array}{l}\text { 1. Production must start in equilibrium with } \\
\text { orders. }\end{array}$ & 0.53 & 0.72 & 0.33 & 33.8 & 0.001 & 0.57 & 0.47 & 2.3 & 0.13 \\
\hline $\begin{array}{l}\text { 2. Production must be constant prior to time } 5 \\
\text { and indicate a lag of four weeks in the } \\
\text { response to the step increase in orders. }\end{array}$ & 0.44 & 0.59 & 0.29 & 20.3 & 0.001 & 0.46 & 0.41 & 0.6 & 0.43 \\
\hline $\begin{array}{l}\text { 3. Production must overshoot orders to } \\
\text { replenish the inventory lost during the initial } \\
\text { period when orders exceed production. } \\
\text { Production should return to (or fluctuate } \\
\text { around) the equilibrium rate of } 11000 \\
\text { widgets/week (to keep inventory at or } \\
\text { fluctuating around the desired level). }\end{array}$ & 0.44 & 0.63 & 0.23 & 36.5 & 0.001 & 0.53 & 0.30 & 11.5 & 0.001 \\
\hline $\begin{array}{l}\text { 4. Conservation of material: The area enclosed } \\
\text { by production and orders during the } \\
\text { overshoot of production (when } \\
\text { production > orders) must equal the area } \\
\text { enclosed by orders less production (when } \\
\text { production < orders). }\end{array}$ & 0.11 & 0.12 & 0.10 & 0.06 & 0.80 & 0.16 & 0.05 & 2.9 & 0.09 \\
\hline $\begin{array}{l}\text { 5. Inventory must initially decline (because } \\
\text { production < orders). }\end{array}$ & 0.68 & NA & 0.68 & NA & NA & 0.77 & 0.55 & 6.1 & 0.01 \\
\hline $\begin{array}{l}\text { 6. Inventory must recover after dropping } \\
\text { initially. }\end{array}$ & 0.56 & NA & 0.56 & NA & NA & 0.66 & 0.43 & 5.6 & 0.02 \\
\hline $\begin{array}{l}\text { 7. Inventory must be consistent with the } \\
\text { trajectory of production and orders. }\end{array}$ & 0.10 & NA & 0.10 & NA & NA & 0.14 & 0.06 & 1.6 & 0.21 \\
\hline Mean for all items & 0.41 & 0.50 & 0.32 & $t=5.11$ & 0.0001 & 0.46 & 0.33 & $t=3.35$ & 0.001 \\
\hline
\end{tabular}

$\mathrm{I}=$ Inventory graph; $\sim \mathrm{I}=$ No Inventory graph. $\mathrm{BG}=$ Beer game experience; $\sim \mathrm{BG}=$ no beer game experience. Points $4-7$ do not apply to the $\sim$ I treatment. The $\chi^{2}$ statistic tests the hypothesis that performance on the two treatment conditions (I vs $\sim$ I or BG vs $\sim \mathrm{BG}$ ) is the same.

at that level. Actual inventory, given the subject's production path, would fall linearly to 46000 and remain there. ${ }^{7}$ In Figure 10(b) the subject correctly shows production lagging orders, but again, there is no production overshoot. Inventory falls roughly linearly through week 10, while given the production path as drawn it would actually fall at a diminishing rate. The subject then shows inventory rising, even though production equals orders after week ten.

The vast majority (89 percent) of subjects did not draw trajectories for inventory that were consistent with the production path they chose. The subject in Figure 10(c) correctly shows the production lag and the production overshoot (which, however, is too large), but shows inventory immediately dropping in week 5 to 46000 units. Inventory then rises through about week 10 even though the subject shows production below orders. Inventory then stabilizes, though the subject shows production exceeding orders. Similar 
Fig. 10. Typical erroneous subject responses to the manufacturing case

Fig. 10. (continued)
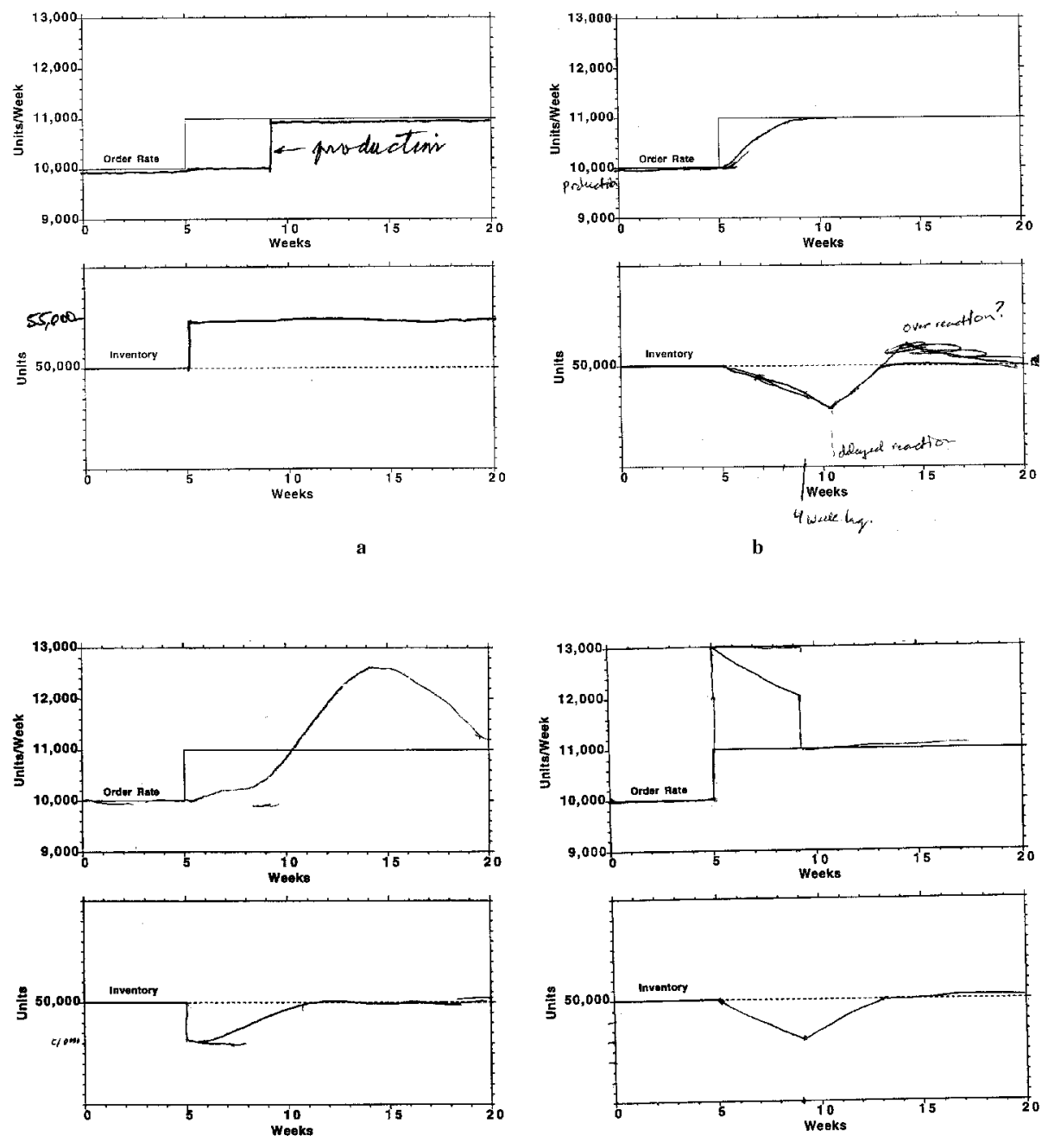

d

problems are illustrated in Figure 10(d). In addition, this subject fails to account for the time delay, showing production jumping in week 5 to 13000 units/week and returning to equilibrium by week 9 . However, the subject shows inventory falling linearly through week 9 at the same time production is shown exceeding orders. Inventory then rises linearly back to equilibrium while production is equal to orders.

Figure 10(e) shows another subject who fails to show the time delay. This subject shows production increasing before orders, while the instructions state that the change in orders is unanticipated. In addition, the subject's 
Fig. 10. (continued)
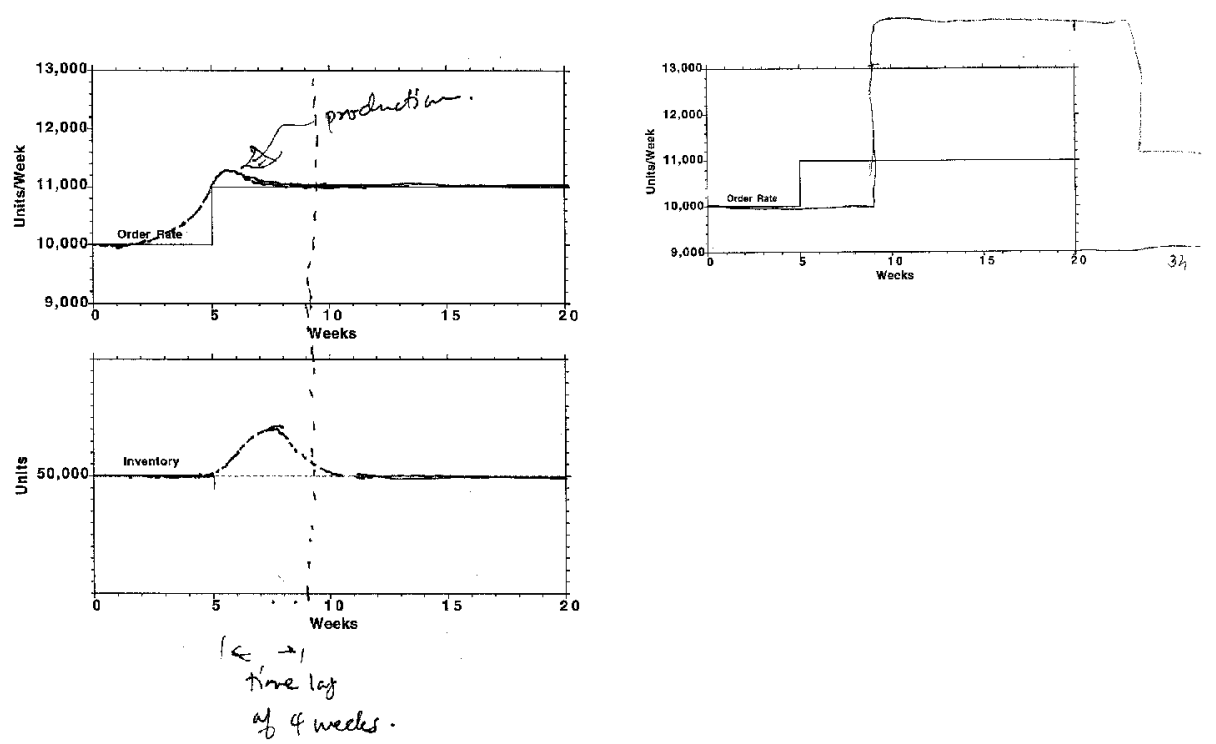

inventory trajectory is inconsistent with the production path. The subject shows inventory constant through week 5, although production is drawn exceeding orders. Inventory then falls while production equals orders. This subject reported that he had a Ph.D. in "nonlinear control theory."

Figure 10(f) shows a subject who apparently understands that production must overshoot but grossly overestimates its magnitude. This subject had the $\sim$ I condition, so we do not know what the subject thought the trajectory of inventory would be. However, the area of the overshoot drawn by the subject is about 3000 units/week $\times 15$ weeks $=45000$ units, more than ten times greater than the 4000 needed to bring inventory back to its desired value.

We hypothesized that subjects would find it easier to respond correctly in the inventory graph condition since the presence of the graph would make it more likely that they would think about the trajectory of inventory. Overall performance in the inventory graph condition, however, is significantly worse than in the no-graph condition $(t=5.11, p<0.0001)$. Comparing performance in the I and $\sim$ I conditions only for the criteria related to the production trajectory (items $1-4$ in Table 5), we see that performance in the inventory graph condition is worse on all items, and that these differences are highly significant (except for item 4, conservation of material, where performance is extremely poor for all). For example, 63 percent of those in the $\sim$ I condition correctly showed production overshooting orders, compared to only 23 percent of those in the I condition. Thus in contrast to our hypothesis, subjects asked explicitly to sketch the trajectory of inventory had a more difficult time correctly 
specifying the trajectory of production than those who were not. It may be that subjects' poor understanding of stock-flow relationships caused them to make more errors on the production task. Alternatively, the drop in performance between the I and $\sim$ I conditions might be explained by the fact that the I condition required subjects to do more in the time available.

Fully 40 percent of the subjects showed production oscillating. We conjectured that students who had played the beer game would recognize the MC task as similar and would be more likely to draw a pattern of oscillation and, indeed, prior beer game play is significantly correlated with an oscillatory production path (Pearson $r=0.24, p=0.0004$ ). About 48 percent of those who had played the beer game showed production oscillating, compared to only 35 percent of those who had not played the game. Interestingly, subjects who had played the beer game did significantly better on the MC task than those who had not (average score of 46 percent vs 33 percent, $t=3.35, p<0.001$ ). There are two competing explanations for the improvement. It may be that playing the beer game gave students insight into the dynamics of the stock management system, so that their higher score indicates that they learned important lessons about delays and stocks and flows. Alternatively, those who had played the game may have remembered the behavior without gaining much appreciation for the underlying stock and flow principles. Specifically, they may recall that in the game production oscillated and that their inventory initially declined, then increased. Any pattern of oscillation necessarily shows production overshooting the order rate, one of the key requirements of a correct response. Similarly, subjects who drew inventory falling and then rising as in the beer game would receive credit for correctly identifying the qualitative behavior of inventory (items 5 and 6 in Table 5). Figure 11 shows a typical response in which production is shown as oscillating around the order rate.

Fig. 11. Typical response of a subject who had played the beer game

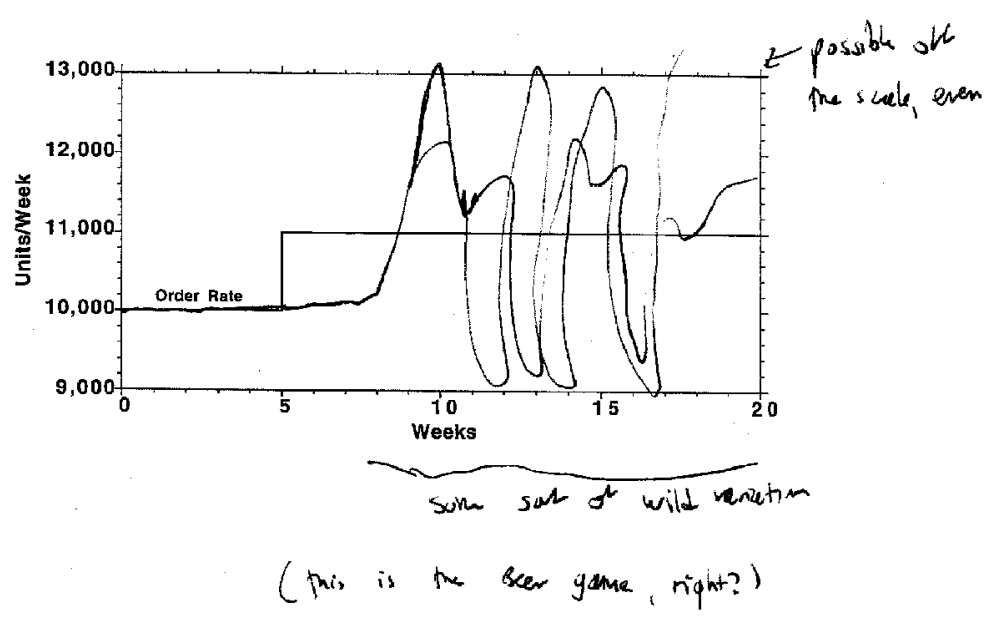


Table 6. Impact of subject demographics on performance (items significant at $p<0.05$ in bold; items significant at $p<0.10$ in italics)

\begin{tabular}{|c|c|c|c|c|c|c|c|c|c|}
\hline \multirow[b]{2}{*}{ Variable } & \multicolumn{3}{|c|}{$\mathrm{BT} / \mathrm{CF}$ task 1} & \multicolumn{3}{|c|}{$\mathrm{BT} / \mathrm{CF}$ task 2} & \multicolumn{3}{|c|}{ MC } \\
\hline & $\overline{\mathrm{DF}}$ & $F$ & $p$ & $\overline{\mathrm{DF}}$ & $F$ & $p$ & $\overline{\mathrm{DF}}$ & $F$ & $p$ \\
\hline Highest prior degree & 6 & 1.99 & 0.074 & 4 & 0.92 & 0.456 & 6 & 0.12 & 0.993 \\
\hline Major field in prior education & 6 & 3.23 & 0.006 & 6 & 1.61 & 0.153 & 6 & 0.43 & 0.857 \\
\hline Current academic program & 3 & 1.10 & 0.354 & 3 & 0.77 & 0.513 & 3 & 0.15 & 0.932 \\
\hline Gender & 1 & 2.32 & 0.131 & 1 & 3.55 & 0.062 & 1 & 3.74 & 0.055 \\
\hline Age & 3 & 0.09 & 0.967 & 3 & 0.36 & 0.782 & 3 & 1.50 & 0.217 \\
\hline Region of origin & 3 & 4.14 & 0.008 & 4 & 2.17 & 0.078 & 4 & 1.95 & 0.105 \\
\hline English as native language & 1 & 0.37 & 0.547 & 1 & 0.29 & 0.591 & 1 & 0.48 & 0.490 \\
\hline Prior beer game play & 1 & 0.00 & 0.993 & 1 & 0.65 & 0.424 & 1 & 4.64 & 0.033 \\
\hline Model DF, Error DF, Total DF & 24 & 96 & 120 & 23 & 96 & 119 & 25 & 164 & 189 \\
\hline Model F-statistic, $p$ value, $R^{2}$ & 2.15 & 0.047 & 0.350 & 1.02 & 0.500 & 0.196 & 1.60 & 0.043 & 0.197 \\
\hline
\end{tabular}

The subject writes in the margin "Some sort of wild variation (this is the beer game, right?)." The subject's response shows no apparent understanding of the stock and flow relationships that require production to overshoot-overshoot is an artifact of the "wild variation."

Close analysis of the results suggests that subjects drawing an oscillation did better as an artifact of drawing an oscillatory response without having any greater understanding of inventory management or stocks and flows (Table 5). Fifty-three percent of those with beer game experience received credit for showing the production overshoot, compared to only 30 percent of those without beer game experience, a significant difference $\left(\chi^{2}=11.5\right.$, $p=0.001)$. Similarly, those with beer game experience did significantly better at showing an initial decline and subsequent recovery in inventory (77 percent vs 55 percent for the initial decline, $\chi^{2}=6.1, p=0.01$, and 66 percent vs 43 percent for the subsequent recovery, $\chi^{2}=5.6, p=0.02$ ). However, there was no significant difference on items $1,2,4$, and 7 . These include conformance with the conservation law and consistency of the production and inventory trajectory. Further, as shown in Table 6, prior beer game experience is significantly related to performance in the MC task, but not to performance in either BT/CF tasks. These results suggest subjects with beer game experience received credit for the production overshoot and inventory decline as artifacts of drawing oscillatory trajectories, but have no better understanding of key attributes of stock and flow structures, including conservation of material and consistency of the net flow and change in the stock.

\section{Impact of subject demographics}

It is plausible to expect that prior education should affect performance. In particular, we hypothesized that subjects with more training in mathematics, the sciences, or engineering would outperform those with training in the social sciences or humanities. To test this hypothesis we ran a variety of general linear 
models relating performance on the different tasks to the various demographic variables subjects reported. Table 6 reports models in which performance on each task is explained by highest prior degree and major field, current academic program, gender, age, region of origin, English as a native language, and prior beer game play (defined as in Table 1). Reporting of demographic data was voluntary; as a result of missing data, the degrees of freedom for each factor may differ across tasks, and the total DF for each model may differ from the number of subjects reported in Table 1 . While some items are significant, there is no consistent pattern. Prior academic field is significant for BT/CF Task 1 and highest prior degree is marginally significant. In addition, as hypothesized, those with technical backgrounds do better than those in the social sciences, but these factors are far from significant in the other tasks. The degree program in which students were currently enrolled was not significant in any of the tasks. The results provide only limited support for the hypothesis that prior training in the sciences helps performance. It is possible that there simply is insufficient variation in the subject pool to detect any effects. Other demographic factors also appear to have only a weak impact. Age is not significant. Performance did not depend on whether English was the subject's first language, but region of origin is significant for BT/CF Task 1, and marginally significant in BT/CF 2 and the MC task. Subjects from North America generally did better. There is a suggestion of a gender effect. Males outperform females on all three tasks, though the effect is only marginally significant.

\section{Discussion}

The results strongly suggest that highly educated subjects with extensive training in mathematics and science have poor understanding of some of the most basic concepts of system dynamics, specifically stocks and flows, time delays, and feedback. The errors are highly systematic and indicate violations of basic principles, not merely calculation errors. Subjects tend to violate fundamental relationships between stocks and flows, including conservation of matter, as shown by the large fraction of respondents in the MC task who drew trajectories for production and inventory that were inconsistent with one another. This result is further reinforced by the significant deterioration in results between BT/CF task 1 and BT/CF task 2: Subjects have poor understanding of the relationship between the net flow into a stock and the slope of the stock trajectory. Many subjects do not understand the relationship between the area enclosed by the net rate into a stock over some interval and the change in the stock over the interval.

Many subjects appear to believe that the stock trajectory should have the same qualitative shape as the net rate. In BT/CF task 1, the net rate is discontinuous and 11 percent of the subjects drew stock trajectories that were also discontinuous, similar to the subject shown in Figure 8(a). In BT/CF task 2, 
the net rate is continuous and only two of 150 (1.3 percent) of the subjects drew discontinuous trajectories for the stock, the only criterion on which the subjects did better on task 2 than task 1 . However, 72 of 150 subjects in task 2 (48 percent) drew stock trajectories with discontinuous slopes, similar to the net rate [as illustrated by Figure 9(a)]. We conjecture that subjects with weak understanding rely on a heuristic that matches the shape of the output of the system to the shape of the input. To illustrate how far wrong such intuitive matching is, plot the derivative of the stock trajectories in Figures 8 and 9 and compare them to the actual net rate.

The two features that subjects find problematic - that the slope of the stock is the net flow and that the change in the stock over an interval is the area enclosed by the net rate in that interval-are the two fundamental concepts of calculus. One might argue that calculus represents rather advanced mathematics, so the failure of the subjects to do well on these tasks is not too worrisome. Such a view, we believe, is erroneous. First, essentially every subject in our experiments had taken calculus (it is a prerequisite for admission to the Sloan School). Many had years of coursework and even undergraduate or graduate degrees in mathematics, engineering, or the sciences. Nevertheless, there is only a weak relationship between education and performance. For a large fraction of the subjects, training and experience with calculus and mathematics did not translate into an intuitive appreciation of accumulations, of stocks and flows.

More importantly, these tasks do not require subjects to use any of the analytic tools of calculus; no derivatives need be taken, no integrals written or evaluated. The tasks can be answered without use of any mathematics beyond simple arithmetic (and perhaps the formulae for the area of rectangles and triangles). The concepts of accumulation, though formalized in calculus, are common and familiar to all of us through a host of everyday tasks, including filling a bathtub, managing a checking account, or controlling an inventory.

We turn now to consider alternative explanations for the results. One possibility is that the subjects did not put much effort into the tasks because there was insufficient incentive. Economists generally argue that subjects should be paid in proportion to performance in experiments and question results in which performance incentives are weak (Smith 1982). In a review of more than 70 studies, Camerer and Hogarth (1999) found that incentives sometimes improved performance. In other cases even significant monetary incentives did not improve performance or eliminate judgmental errors. In some cases incentives worsened performance. It is possible that additional incentive in the form of grades or monetary payment would improve the results. On the other hand, if we ask students "What is $2+2$ ?" essentially all answer "four" without hesitation, even without grades or payment. The knowledge required in our experiment is nearly as basic and should be nearly as automatic. The resolution of this issue awaits future research.

It is also possible that the subjects were given insufficient time. This question also must be left for future research. We expect that more time would improve 
performance, but suspect many of the same errors will persist, particularly violations of conservation laws and inconsistent net rate and stock trajectories. Given the importance and ubiquity of stock and flow structures, people should be able to infer their dynamics quickly and reliably; their failure to do so even in a relatively short period of time is a further indicator of their poor understanding of these critical concepts.

Advocates of the naturalistic decision making movement argue that many of the apparent errors documented in decision-making research arise not because people have poor reasoning skills, but as artifacts of unfamiliar and unrealistic laboratory tasks. While strongly emphasizing the bounded rationality of human decision making, they argue that people can often perform well in complex decision-making settings because we have evolved "fast and frugal" heuristics that "are successful to the degree they are ecologically rational, that is, adapted to the structure of the information in the environment in which they are used..." (Gigerenzer et al. 1999: vii). Perhaps people understand stocks, flows, delays, and feedback well and can use them in everyday tasks, but do poorly here because of the unfamiliar and unrealistic presentation of the problems. After all, people do manage to fill and drain their bathtubs and manage their checking accounts. We agree that people can perform well in familiar, naturalistic settings yet poorly on the same type of task in an unfamiliar setting. Our decision making capabilities evolved to function in particular environments; to the extent that the heuristics we use in these environments are context-specific, performance will not necessarily transfer to other situations, even if their logical structure is the same.

What is the naturalistic context for this type of task? More and more of the pressing problems facing us as managers and citizens alike involve long delays. The long time scale for the consequences of many decisions means there is little opportunity for learning through outcome feedback and thus for the evolution of high-performing decision rules (Sterman 1994). Increasingly, we are faced with tasks involving significant stocks and flows, time delays, and feedbacks, tasks for which the naturalistic context is a spreadsheet, a graph, or a text-the same type of presentation as in our tasks. Managers are called on to evaluate spreadsheets and graphs projecting revenue and expenditure, bookings and shipments, hiring and attrition. These modes of data presentation are not unique to business. Epidemiologists must understand the relationship between the incidence and prevalence of disease, urban planners need to know how migration and population are related, and everyone, not only climatologists, needs to understand how emissions of greenhouse gases affect their concentration in the atmosphere and how that concentration in turn alters heat flux and global temperatures. For many of the most pressing issues in business and public policy, the mode of data presentation in our tasks is the naturalistic context.

There is abundant evidence that sophisticated policymakers suffer from the same errors in understanding stocks and flows that we observe in our 
experiments. To take only one example, Homer (1993) used basic stock-flow logic to show that US government survey data on the prevalence of cocaine use could not be correct. The number of people who reported that they had used cocaine in the past month showed a sharp drop starting around the late 1980s. Yet, at the same time, cocaine related arrests, medical emergencies, and deaths were growing exponentially, while prices fell and purity increased, suggesting rising use. Which data were correct? The government also asks survey respondents if they have ever used cocaine. However, these lifetime prevalence estimates were not much discussed in policy circles because they did not distinguish between current and former users. Homer realized, however, that this feature meant that the lifetime prevalence estimates could be used to provide a strong check on the accuracy of the survey data.

The number of people who have ever used cocaine is a stock increased by the rate at which people try the drug for the first time. It is decreased only by death. The reported decline in lifetime prevalence was physically impossible-even if everyone in the country "just said no," cutting the inflow of new users to zero, lifetime prevalence could not decline that fast. The survey assumed, however, that the fraction of people responding truthfully was constant and that the sample was properly stratified. Instead, as people realized that cocaine was actually harmful, and as its social and legal acceptability fell, more and more current and former users simply lied about their drug use. Further, since heavy cocaine users were more likely to be homeless or live in poor and dangerous neighborhoods, they were less likely to be included in the survey. Homer showed that the actual population of people who had ever used cocaine must have continued to grow, although at a diminishing rate, and likely reached more than 60 million people by 1995, compared to the government's estimate of about 25 million. Until Homer's work no-one in the drug policy establishment pointed out the inconsistency. These results had large public policy implications, since the Bush administration used the erroneous survey data showing large drops in cocaine use to argue that the war on drugs, with its focus on interdiction and incarceration rather than prevention, was working. Billions of dollars were spent on such interdiction efforts, but, as MacCoun and Reuter (1997: 47) put it, "The probability of a cocaine or heroin seller being incarcerated has risen sharply since about 1985 but that has led neither to increased price nor reduced availability."

Assuming our results withstand replication and additional testing, what are the implications for system dynamicists and teachers interested in developing the systems thinking capabilities of their clients and students? It appears that we should spend considerable time on the basics of stocks and flows, time delays, and feedback, with an emphasis on developing intuition rather than the mathematics. Of course, we believe that mathematics and formal theory are important, and no good system dynamics education can do without them. However, our results suggest that good mathematics training alone is not sufficient to develop a practical, common-sense understanding of the most basic 
building blocks of complex systems. We suggest that students should be given extensive opportunities for hands-on practice in both identifying and mapping stock and flow structures and graphical integration and differentiation.

Our results also suggest implications beyond system dynamics curriculum and pedagogy. We found that students have difficulty with basic concepts of great importance in many disciplines and real-world tasks. These findings mirror similar results that learners hold many misconceptions about a variety of concepts, such as probability or Newton's laws (Grotzer 1993; Grotzer and Bell 1999). Several decades of research in science education show that many students hold intuitive theories quite different from those of scientists, and that these ideas are highly resistant to change (Sadler 1998). These beliefs are not limited to naiveté about physical principles such as "heavy objects fall faster than light ones" but include a staggering array of magical and superstitious beliefs antithetical to the principles of scientific method itself (Sterman 1994). System dynamics educators can learn much from attempts to overcome these misconceptions in science and mathematics education.

At the same time, educators in the $\mathrm{K}-12$ arena can also learn from our results. ${ }^{8}$ Frankly, the concepts of accumulations and time delays are so basic they should already be well understood by the time students reach college, much less graduate school. As system dynamics educators, we should not have to take valuable class time to teach what are, essentially, remedial lessons on how accumulations work, how to read graphs, and so on. This is not merely a problem about dynamics. A recent study by the American Association for the Advancement of Science reviewed popular algebra texts used in US schools. The panel concluded that the reason students are not learning the concepts of algebra is that the books (and by implication, the curricula and pedagogy) "don't explain how algebra calculations will relate to everyday life" according to the Boston Globe (2000). In rating the texts, the panel found none of them to be excellent. "Five-including the three most widely used in American classrooms - were rated so inadequate that they lack potential for student learning."

Of course, our results are preliminary and much more work is needed. We are developing additional items to assess other dimensions of complexity such as the ability to recognize and interpret feedback relationships, the ability to recognize and analyze nonlinear relationships between cause and effect, and the ability to estimate and analyze the impact of time delays.

There is additional work to be done exploring how performance depends on factors such as gender, prior education and experience, and other demographic variables. We plan to expand the subject pool to include a broader range of people, from K-12 students to experienced managers. Differences in performance among these groups may provide important clues to the source of people's learning about these concepts. Interviews and verbal protocols have proven productive in prior evaluative research on students' alternative conceptions of scientific principles (Sadler 1998; Duckworth 
1987, Osborne and Gilbert 1980) and we expect such tools will be useful in understanding the sources of student difficulties with systems thinking concepts as well.

The inventory should help educators and researchers establish a baseline measure of people's ability to understand the elements of dynamic complexity and use them effectively in everyday reasoning. It also provides a preliminary tool to measure the impact of various types of systems thinking training. Ultimately, evaluative research on the efficacy of systems thinking training and interventions should assess whether and how an intervention affected the behavior of the participants and the outcomes of new policies and actions taken as a result, not only changes in their attitudes, thinking, and skills.

\section{Acknowledgement}

Financial support for this project was provided by the MIT Sloan School of Management Organizational Learning Fund. Nelson Repenning graciously permitted us to administer the tasks in his introductory system dynamics class. We also thank Jim Doyle, Michael Radzicki, Terry Tivnan and the referees for helpful comments. Christopher Hunter assisted with data entry.

\section{Notes}

1. We tested two versions of BT/CF task 1. One (shown in Figures 1 and 2) included the scale and units of measure for the stock. The second omitted the units and scale; subjects had to specify their own scale. There were no significant differences in performance between the scale/no-scale conditions (the hypothesis that the means for the units and no-units conditions were equal could not be rejected at $p \approx 0.86$ ), so we dropped this treatment in BT/CF task 2.

2. Any subject who recalls elementary calculus knows that the trajectory of the stock follows a parabola within each segment. However, we did not require subjects to recognize or indicate this in their responses. They received full marks as long as they showed the slope for the stock changing in the proper fashion as indicated in item 5, whether it was parabolic or not.

3. We did not penalize subjects if they selected other patterns for the delay (such as some adjustment before week 9 and some after, as would be generated by a finite-order material delay), as long as production did not begin to increase until after the step increase in orders.

4. We also hypothesized that some subjects might not appreciate the negative feedback loop through which the firm controls inventory. To further direct attention to the inventory control process, we created a "feedback hint" 
treatment with two levels: in the Feedback hint $(\mathrm{H})$ condition, the task description included this sentence:

Because customer orders are quite variable, the firm strives to maintain an inventory of 50,000 units to provide excellent customer service (that is, to be able to fill essentially $100 \%$ of every order), and they adjust production schedules to close any gap between the desired and actual level.

In the No Hint $(\sim \mathrm{H})$ condition the phrase "and they adjust production schedules to close any gap between the desired and actual level"was omitted. In the first administration of the MC task all four combinations of the inventory graph and feedback hint treatments were given. Performance on the two hint conditions was almost identical $(\mathrm{H}=0.426 ; \sim \mathrm{H}=0.435$; the hypothesis that these means are equal cannot be rejected at $p \approx 0.86$ ), so in the second administration of the MC task all subjects received the $\mathrm{H}$ condition and we pooled all responses in the analysis.

5. The Paper Fold task is described in Sterman (2000), ch. 8, and tests understanding of positive feedback and exponential growth. We will report the results of this task in another article.

6. Between the first and second rounds students covered the system dynamics perspective, the concept of feedback, and causal loop diagrams; stocks and flows were introduced after they did the BT/CF task. Since the class is an elective and there is some enrollment churn in the first weeks, not all those in session 1 were present for session 2, and vice-versa.

7. It is possible that the subject's inventory trajectory represents desired inventory, which the subject may believe should rise by 10 percent so that inventory coverage remains constant. However, the instructions explicitly state that the subjects should draw the trajectory of inventory, and that the desired inventory level is constant at 50000 units. The inventory graph also includes a dotted line at the 50000 unit level to show desired inventory visually.

8. The K-12 grades (Kindergarten-12 ${ }^{\text {th }}$ ) grades typically span ages 5-18.

\section{References}

Ackoff R, Gharajedaghi J. 1985. Toward systemic education of systems scientists. Systems Research 2(1): 21-27.

Bakken BE, Gould JM, Kim D. 1992. Experimentation in learning organizations: a management flight simulator approach. European Journal of Operations Research 59(1): 167-182.

Boston Globe 2000. 27 April: A27.

Boutilier R. 1981. The development of understanding of social systems. PhD Thesis, The University of British Columbia, British Columbia.

Brehmer B. 1992. Dynamic decision making: human control of complex systems. Acta Psychologica 81: 211-241. 
Camerer C, Hogarth R. 1999. The effects of financial incentives in experiments: a review and capital-labor-production framework. Journal of Risk and Uncertainty 19(1-3): $7-42$.

Cavaleri S, Sterman J. 1997. Towards evaluation of systems thinking interventions: a case study. System Dynamics Review 13(2): 171-186.

Chandler M, Boutilier R. 1992. The development of dynamic system reasoning. Contributions to Human Development 21: 121-137.

Dangerfield BC, Roberts CA. 1995. Projecting dynamic behavior in the absence of a model: an experiment. System Dynamics Review 11(2): 157-172.

Diehl E, Sterman J. 1995. Effects of feedback complexity on dynamic decision making. Organizational Behavior and Human Decision Processes 62(2): 198-215.

Dörner D. 1980. On the difficulties people have in dealing with complexity. Simulations and Games 11(1): 87-106.

Dörner D. 1996. The Logic of Failure. Metropolitan Books/Henry Holt: New York.

Doyle J, Radzicki M, Trees S. 1996. Measuring the effect of system thinking interventions on mental models. 1996 International System Dynamics Conference. System Dynamics Society: Cambridge, MA, pp. 129-132.

Doyle J, Radzicki M, Trees S. 1998. Measuring changes in mental models of dynamic systems: an exploratory study. 16th International Conference of the System Dynamics Society, Quebec '98. System Dynamics Society: Quebec City, Canada.

Duckworth E. 1996. The Having of Wonderful Ideas and Other Essays on Teaching and Learning. Teacher's College Press: New York.

Forrester JW. 1961. Industrial Dynamics. MIT Press: Cambridge: Currently available from Pegasus Communications: Waltham, MA.

Frensch PA, Funke J (eds). 1995. Complex Problem Solving-The European Perspective. Lawrence Erlbaum Associates: Mahwah, NJ.

Gigerenzer G, Todd P, ABC Research Group. 1999. Simple Heuristics that Make Us Smart. Oxford University Press: New York.

Gould J (ed.). 1993. Systems Thinking in Education. System Dynamics Review (special issue) $\mathbf{9}(2)$.

Grotzer T. 1993. Children's Understanding of Complex Causal Relationships in Natural Systems. Harvard Graduate School of Education: Cambridge, MA.

Grotzer TA, Bell B. 1999. Negotiating the funnel: Guiding students toward understanding elusive generative concepts. In The Project Zero Classroom: Views on Understanding. Hetland L, Veenema S (eds). Fellows and Trustees of Harvard College: Cambridge, MA.

Homer J. 1993. A system dynamics model of national cocaine prevalence. System Dynamics Review 9(1): 49-78.

MacCoun R, Reuter P. 1997. Interpreting Dutch cannabis policy: reasoning by analogy in the legalization debate. Science 278 (3 October): 47-52.

Mandinach E, Cline H. 1994. Classroom Dynamics: Implementing a Technology-Based Learning Environment. Lawrence Erlbaum Associates: Hillsdale, NJ.

Microworlds Inc. Brochure 1997. Division of GKA Inc., Cambridge, MA 02138.

Osborne R, Gilbert J. 1980. A technique for exploring students' views of the world. Physics Education 15: 376-379.

Ossimitz G. 1996. Development of Systems Thinking. Institute of Educational Research: Bonn, Germany. 
286 System Dynamics Review Volume 16 Number 4 Winter 2000

Paich M, Sterman J. 1993. Boom, bust, and failures to learn in experimental markets. Management Science 39(12): 1439-1458.

Richmond B. 1993. Systems thinking: critical thinking skills for the 1990s and beyond. System Dynamics Review 9(2): 113-134.

Sadler P. 1998. Pyschometric models of student conceptions in science: reconciling qualitative studies and distractor-driven assessment instruments. Journal of Research in Science Teaching 35(3): 265-296.

Senge P. 1990. The Fifth Discipline: The Art and Practice of the Learning Organization. Doubleday: New York.

Senge P, Kleiner A, Roberts C, Roth G, Smith B. 1999. The Dance of Change: Mastering the Twelve Challenges to Change in a Learning Organization. Doubleday: New York.

Smith V. 1982. Microeconomic systems as an an experimental science. American Economic Review 72: 923-955.

Sterman J. 1989a. Misperceptions of feedback in dynamic decision making. Organizational Behavior and Human Decision Processes 43(3): 301-335.

Sterman J. 1989b. Modeling managerial behavior: misperceptions of feedback in a dynamic decision making experiment. Management Science 35(3): 321-339.

Sterman J. 1994. Learning in and about complex systems. System Dynamics Review 10(2-3): 291-330.

Sterman J. 2000. Business Dynamics: Systems Thinking and Modeling for a Complex World. Irwin/McGraw-Hill: New York.

TLC Team Learning Lab Brochure. 1998. The Learning Circle, Sudbury, MA.

Vennix J. 1996. Group Model Building: Facilitating Team Learning Using System Dynamics. Wiley: Chichester.

Zulauf CA. 1995. An Exploration of the Cognitive Correlates of Systems Thinking. Ph.D. Thesis, Boston University, Boston, MA. 